\title{
How Beliefs of the Political Elite and Citizens on Climate Change Influence Support for Swiss Energy Transition Policy
}

\author{
Lorenz Kammermann and Clau Dermont \\ University of Bern
}

\section{Documentation}

May 2018

\begin{abstract}
This paper analyzes factors that lead to opposition towards policies in Switzerland that promote a clean energy transition. During legislative processes, both the elite and general citizens can develop resistance towards such policies. The article considers those two perspectives and determines, on both levels, factors that explain opposition. We also specifically take into account whether climate change skepticism, i.e., questioning that climate change is real and human-induced, is a key factor that leads to opposition. Furthermore, we employ structural equation models to account for interactions between the elite and general citizens. The results show that political actors who reject the idea of man-made climate change also oppose the promotion of a clean energy transition, and more generally that elite actors influence how citizens think about the issue. At the citizen level, an increase in climate change skepticism has a negative impact on levels of support for clean energy policy. The link is mainly determined by party affiliation. We conclude that potential strategies for achieving a clean energy transition should focus on motivating citizens because they generally seem to be less polarized and partisan, and thus less opposed to new solutions, than the elite, who tend to be more constrained in their actions.
\end{abstract}

\section{Setup}

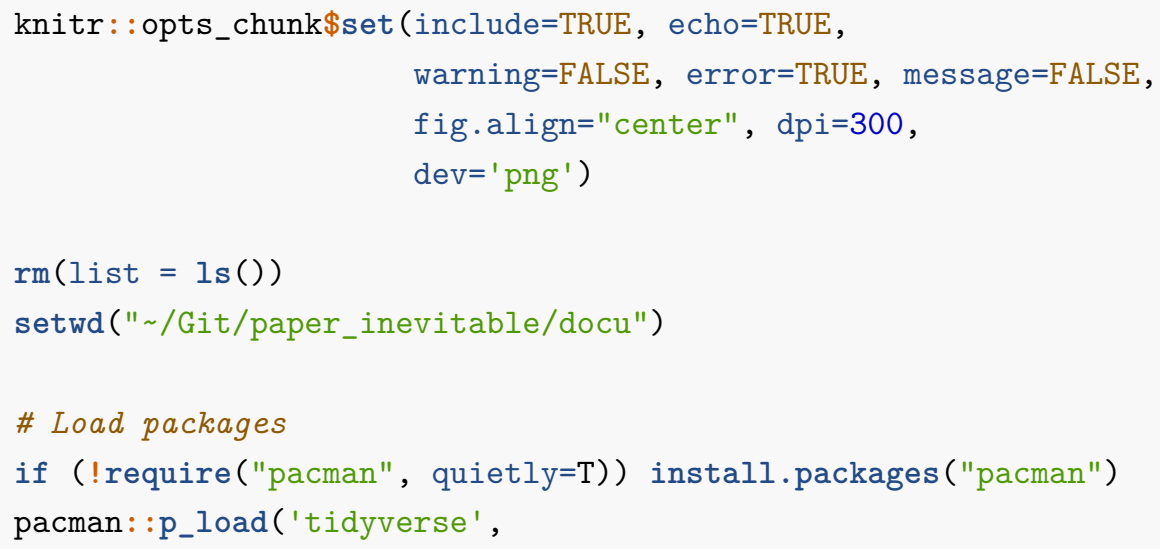




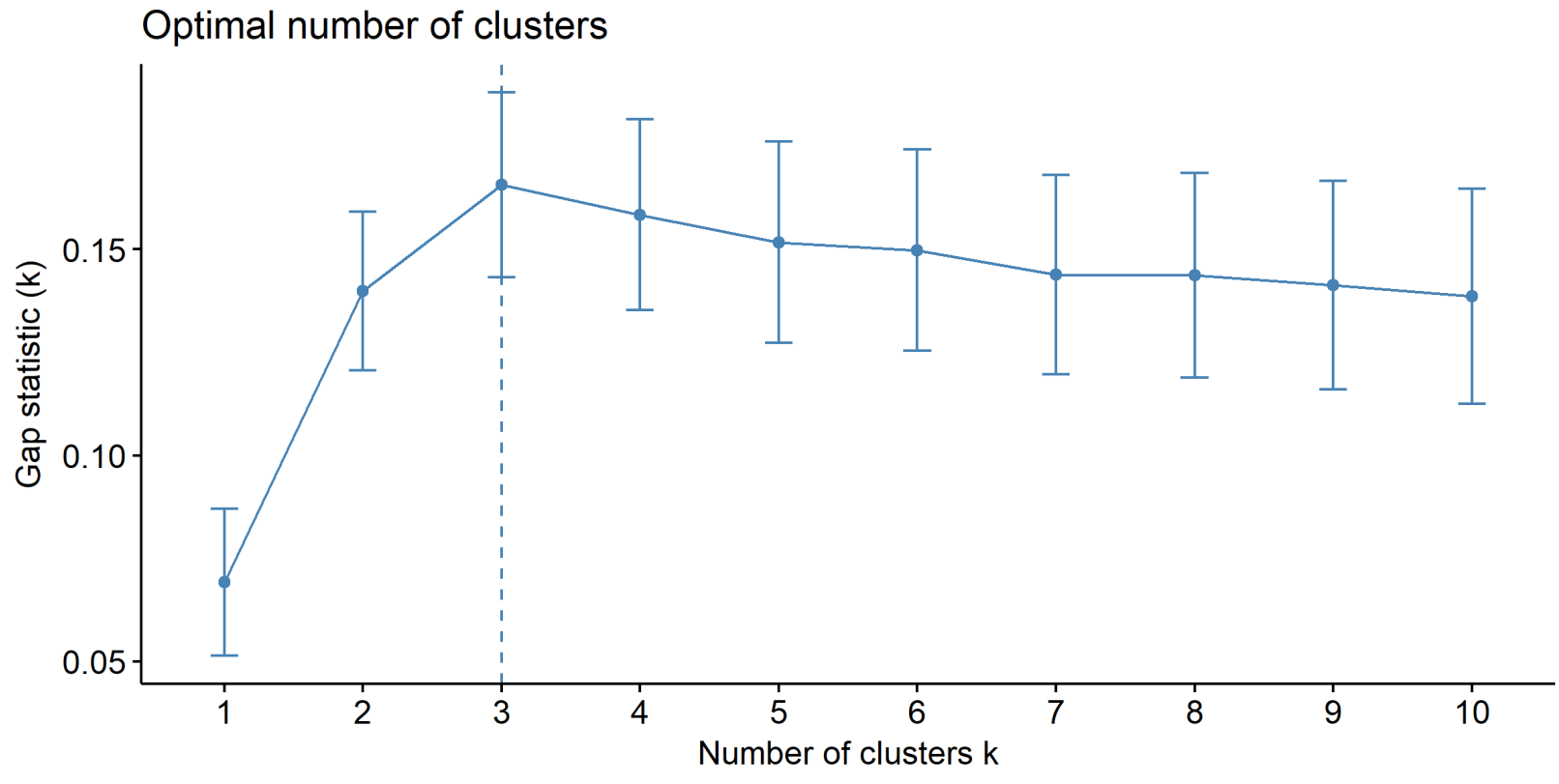

Figure 1: Clusters.

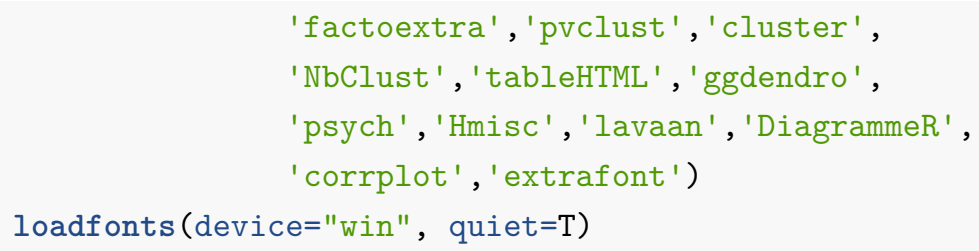

\section{Elite level}

\subsection{Clusters}

On elite level, we first calculate clusters that reflect how the elite (parties, organizations, lobby groups) share or deviate in their preferences and beliefs.

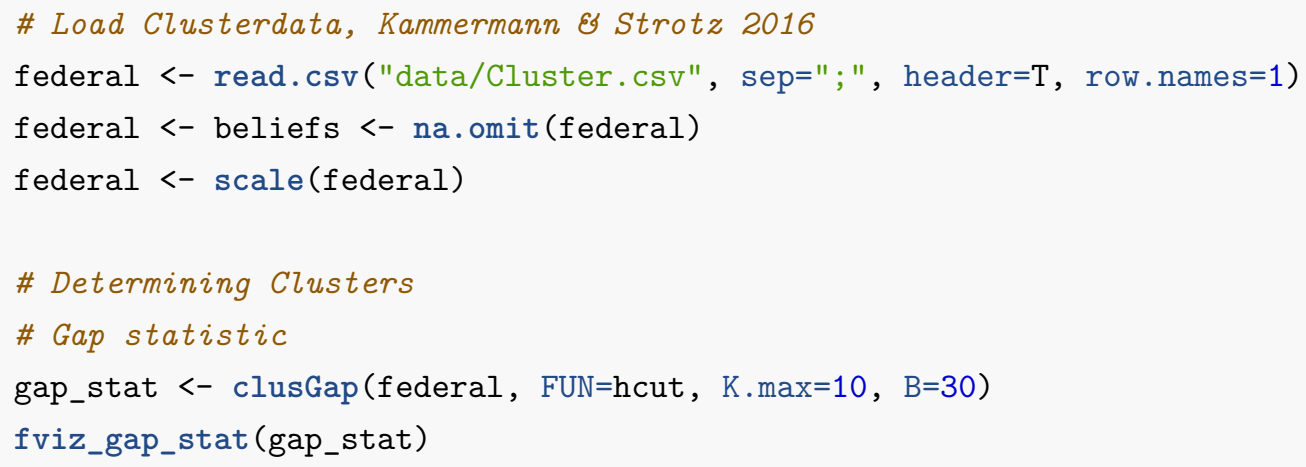


The gap-statstic shows that choosing three clusters would be statistically 'optimal'. However, we are confident that four clusters represent the actual distribution of actors more accuratly on a contextual level. The third cluster's confidence interval indicated in the graph also covers the fourth cluster. We are thus also 'safe' on a statistical level.

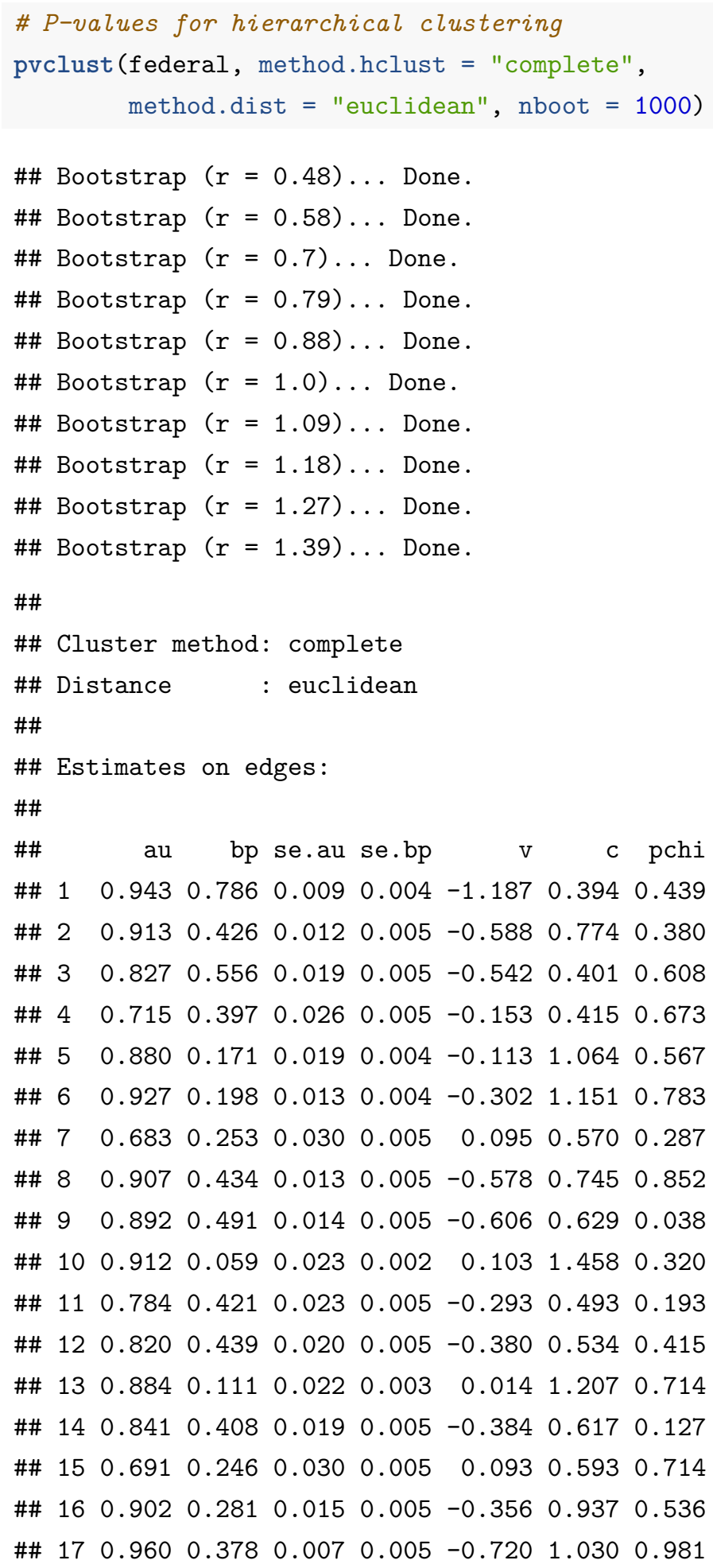




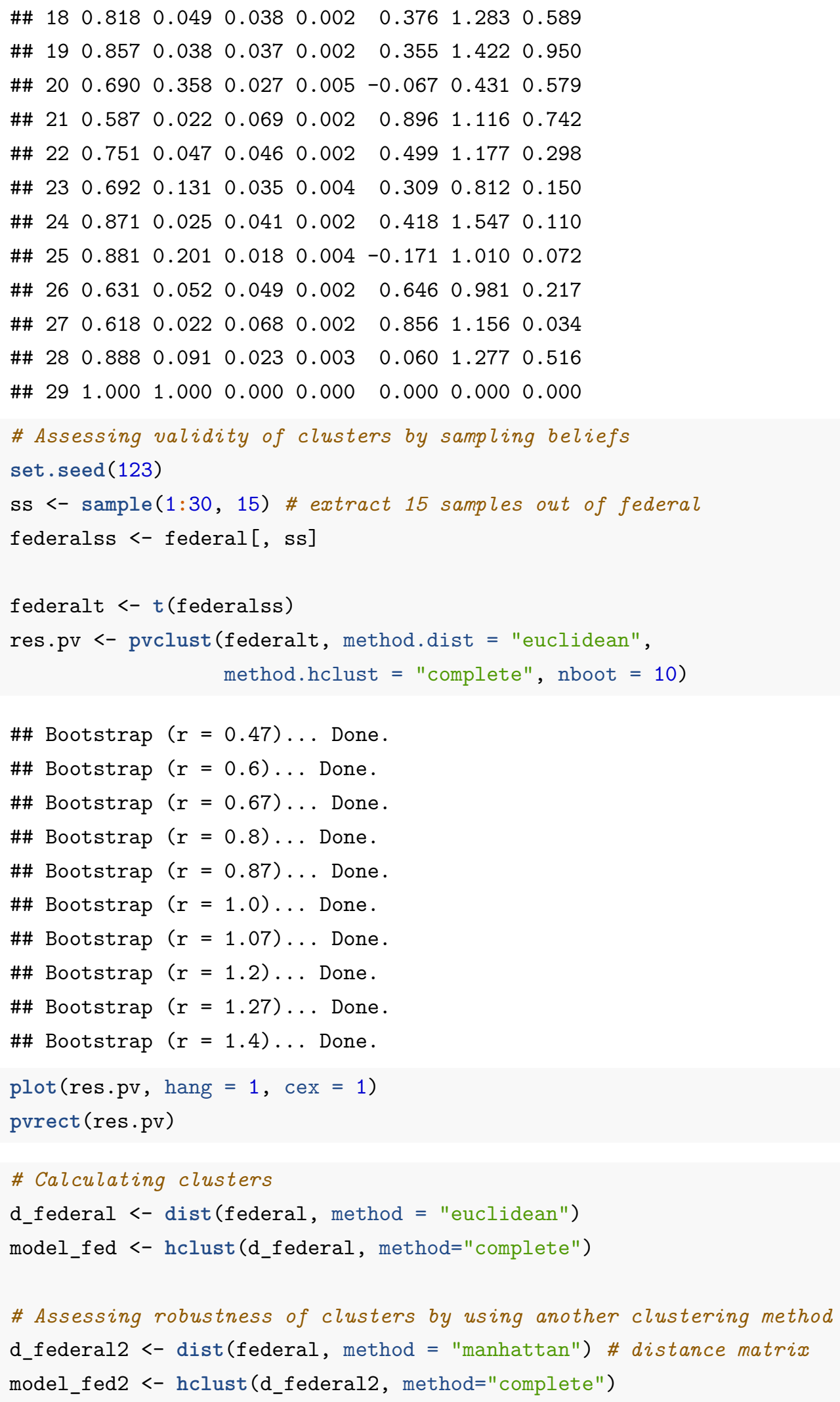




\section{Cluster dendrogram with AU/BP values (\%)}

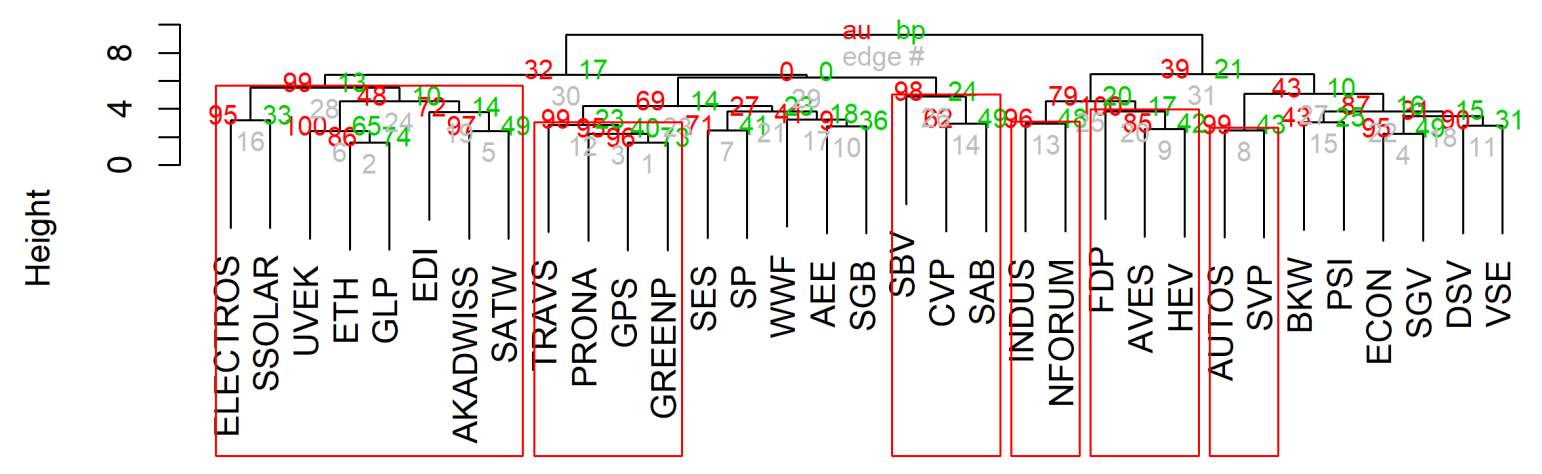

Distance: euclidean

Cluster method: complete

Figure 2: Clusters.

The clusters obtained with the second clustering method stay largely the same as with the euclidean clustering method.

However, a group of three actors (PSI, BKW, \& VSE) switch from the semi-anti cluster to the pro cluster. The specific beliefs of theses three actors show that they belong to the 'least opposed' to the new strategy, from the semi-anti cluster. This is due to the fact that (e.g.) the PSI, as a research center for nuclear energy, will be heavilyaffected by the ban on constructing new reactors. Otherwise, the PSI supports a large part of the beliefs of the pro cluster.

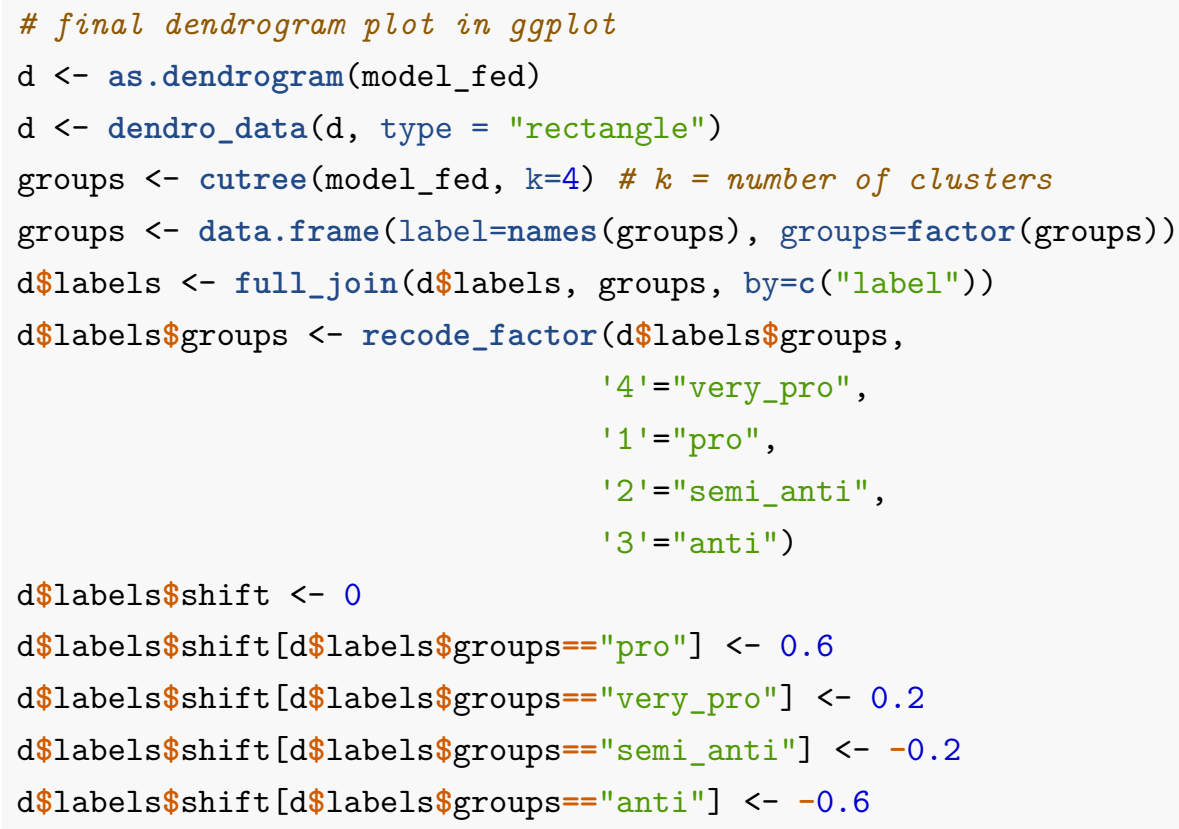




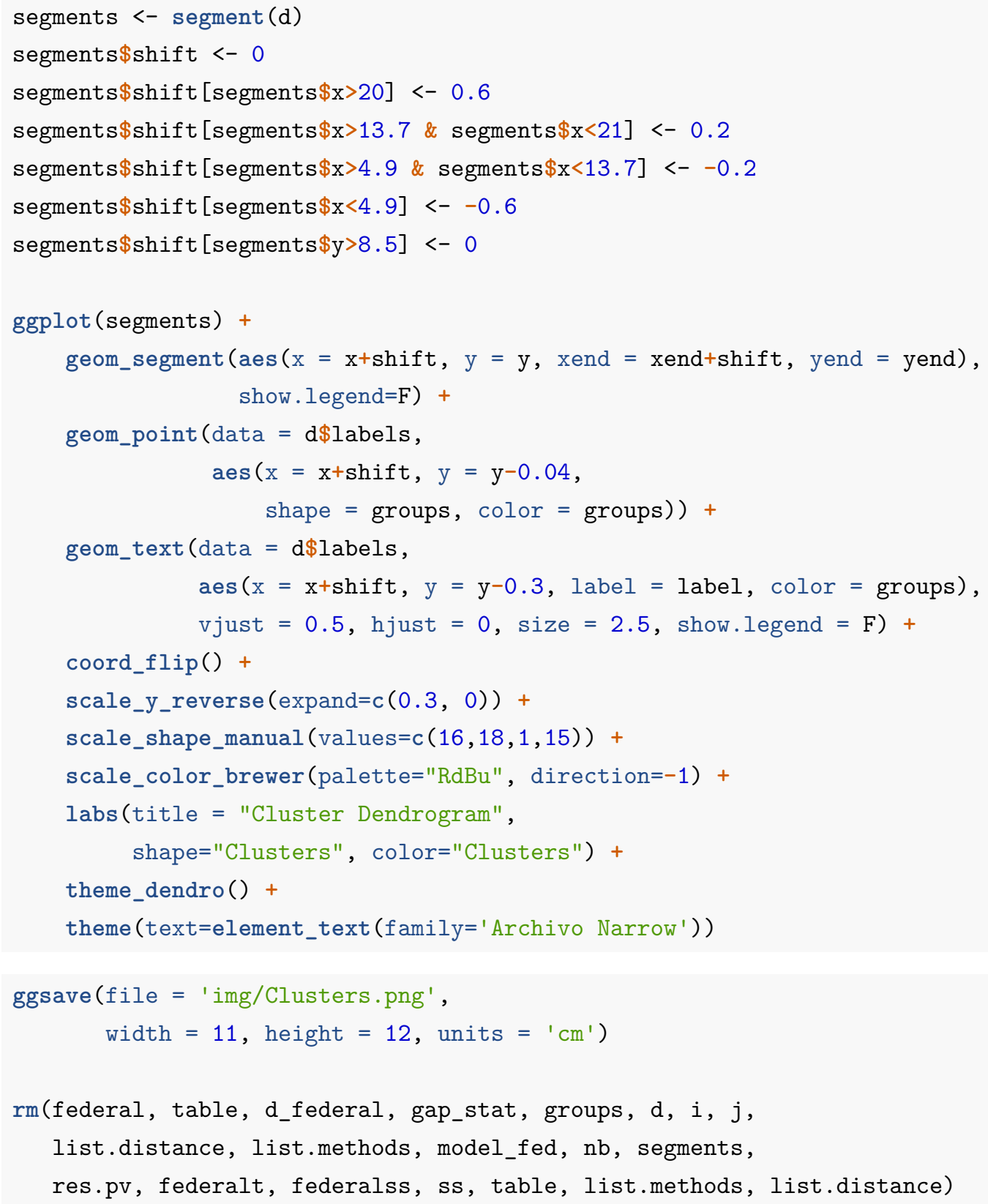

\subsection{Beliefs}

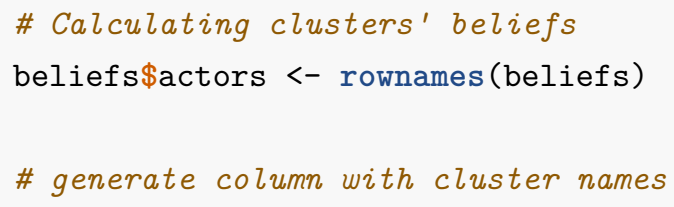




\section{Cluster Dendrogram}

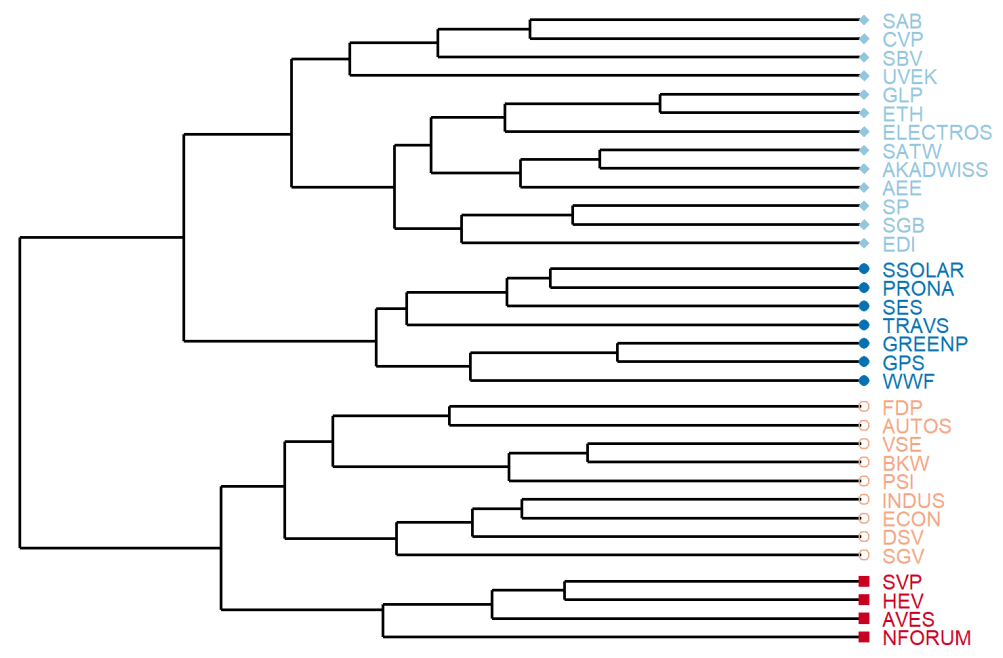

Clusters

- very_pro

pro

semi_anti

- anti

Figure 3: Clusters.

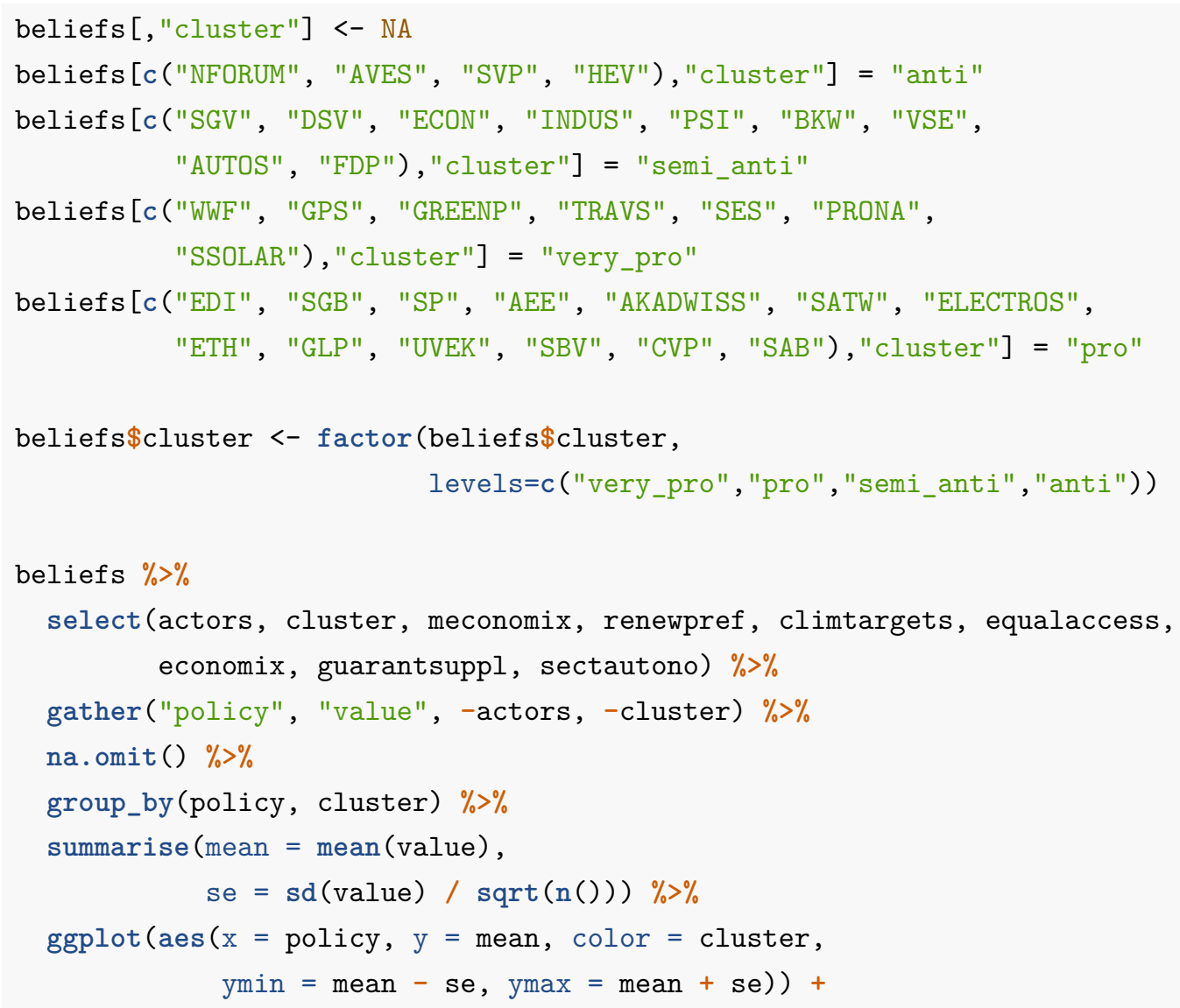




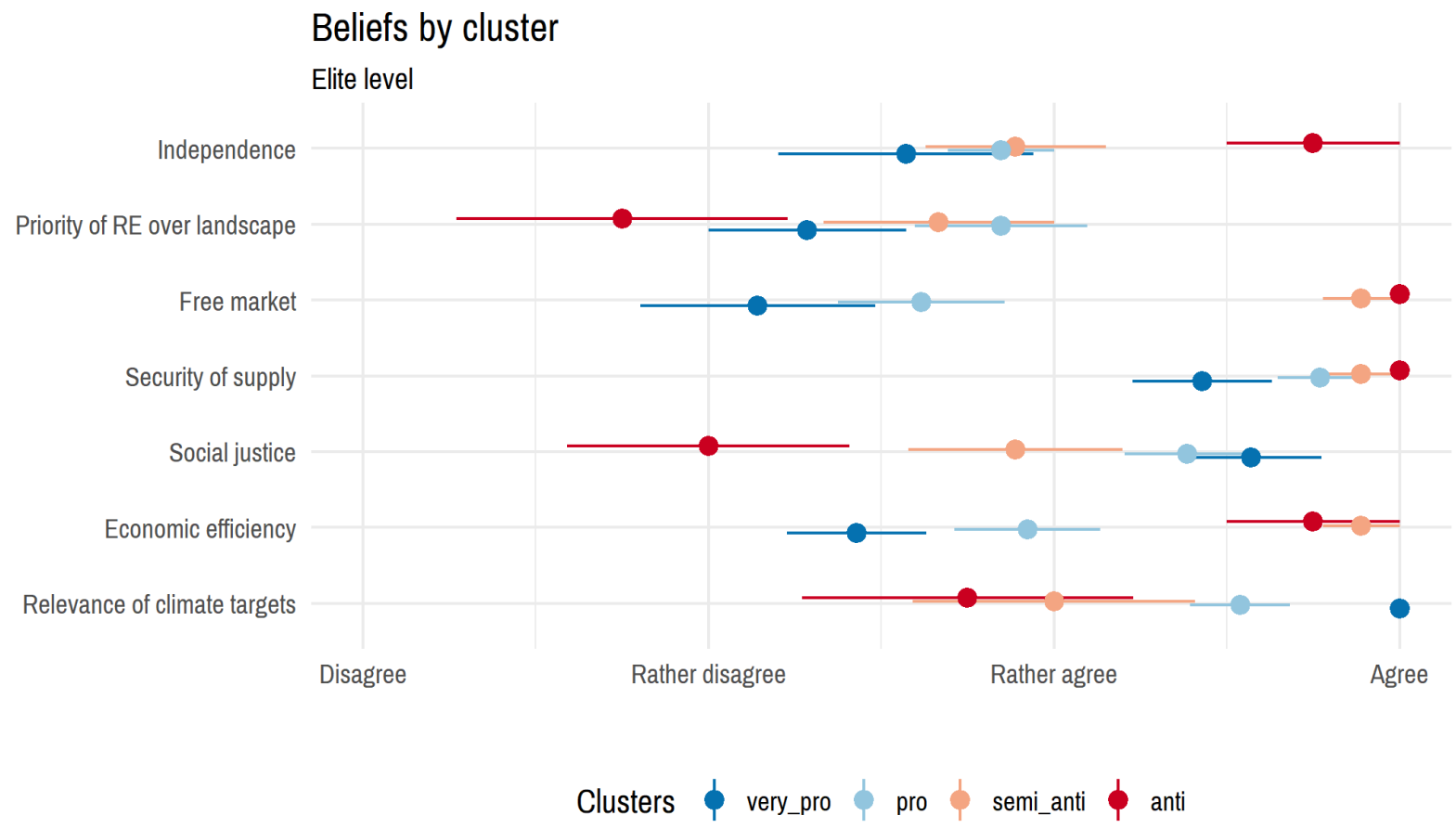

Figure 4: Beliefs, elite level.

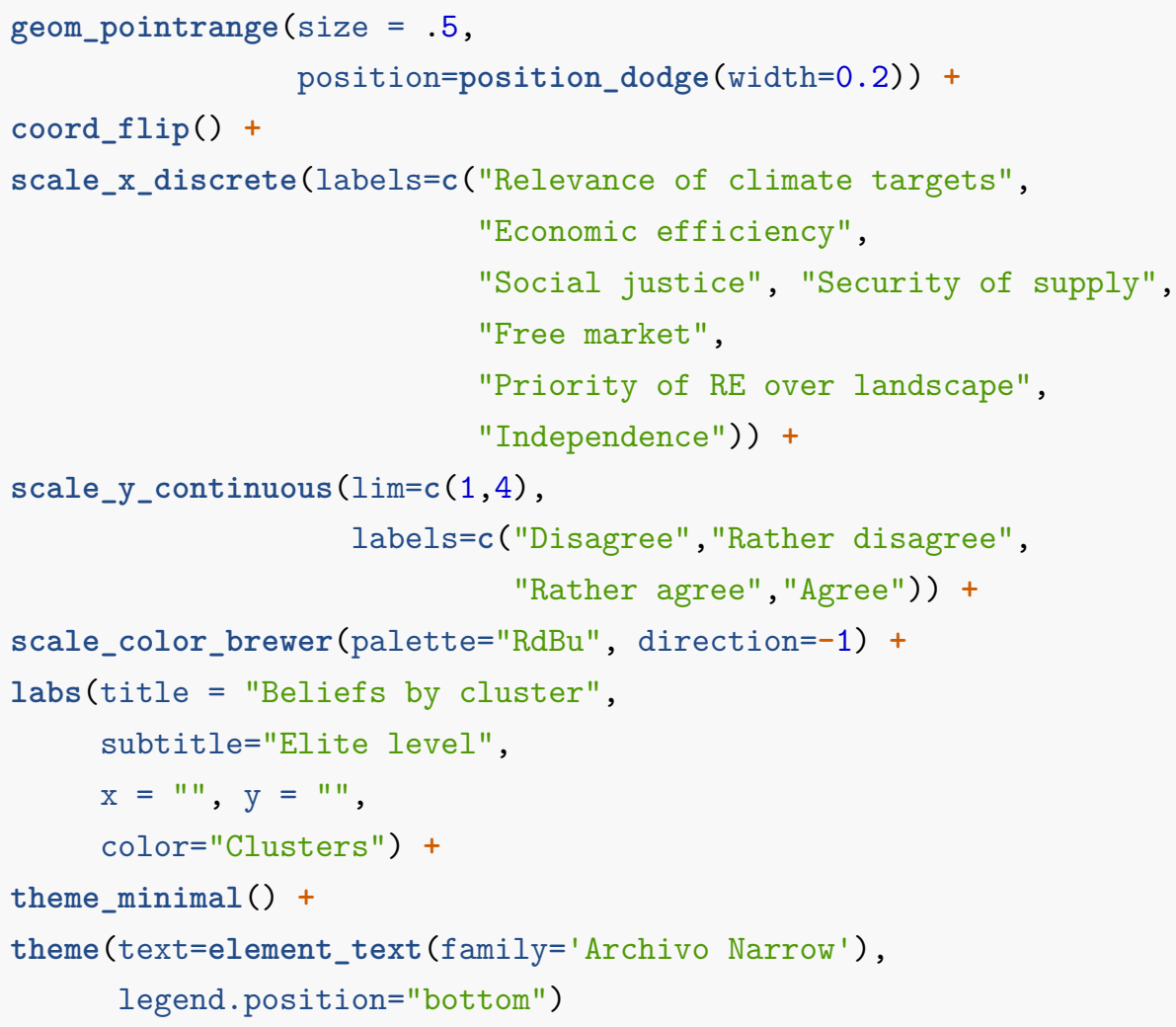




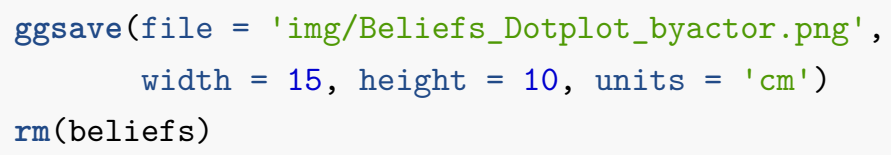

\subsection{Policy preferences}

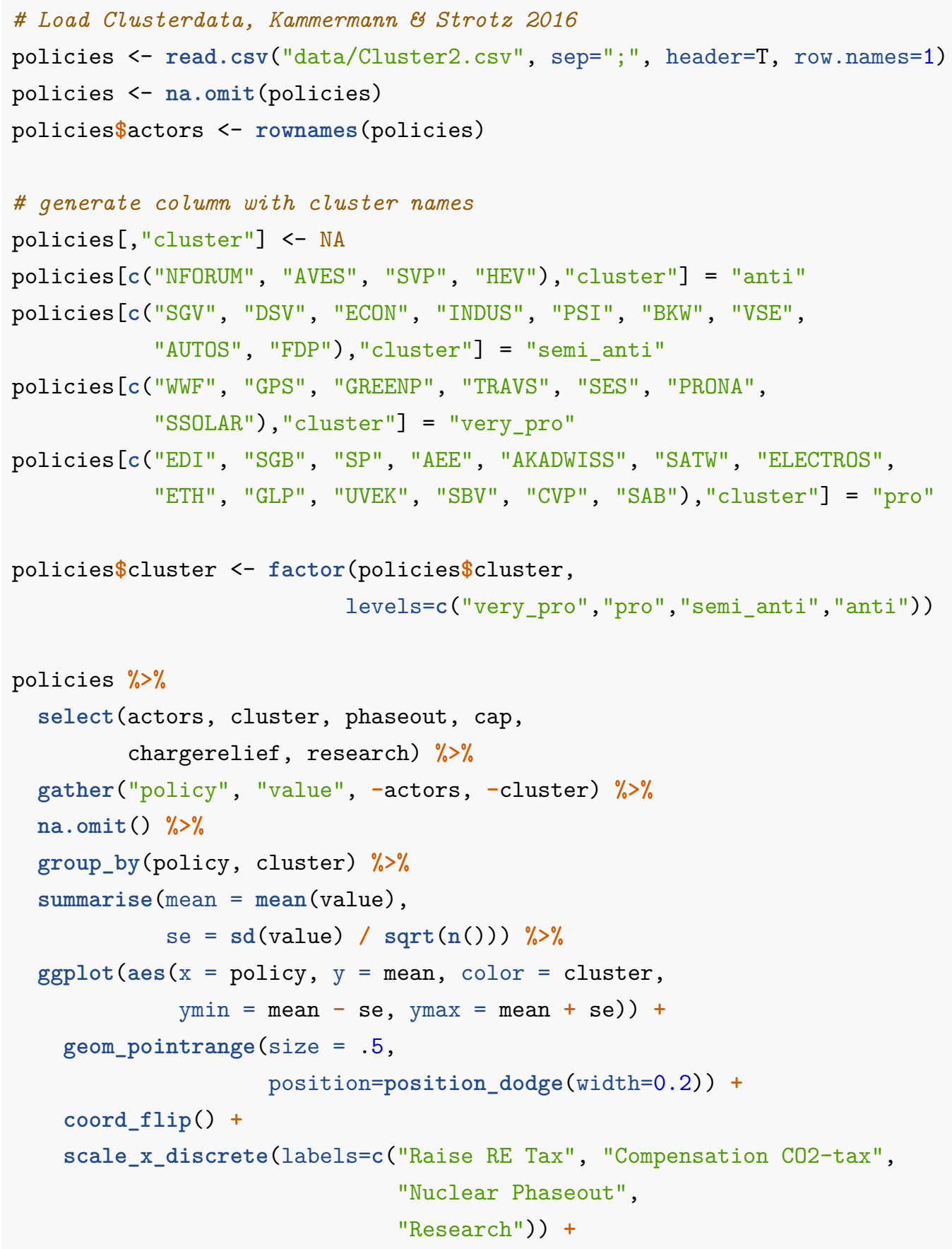




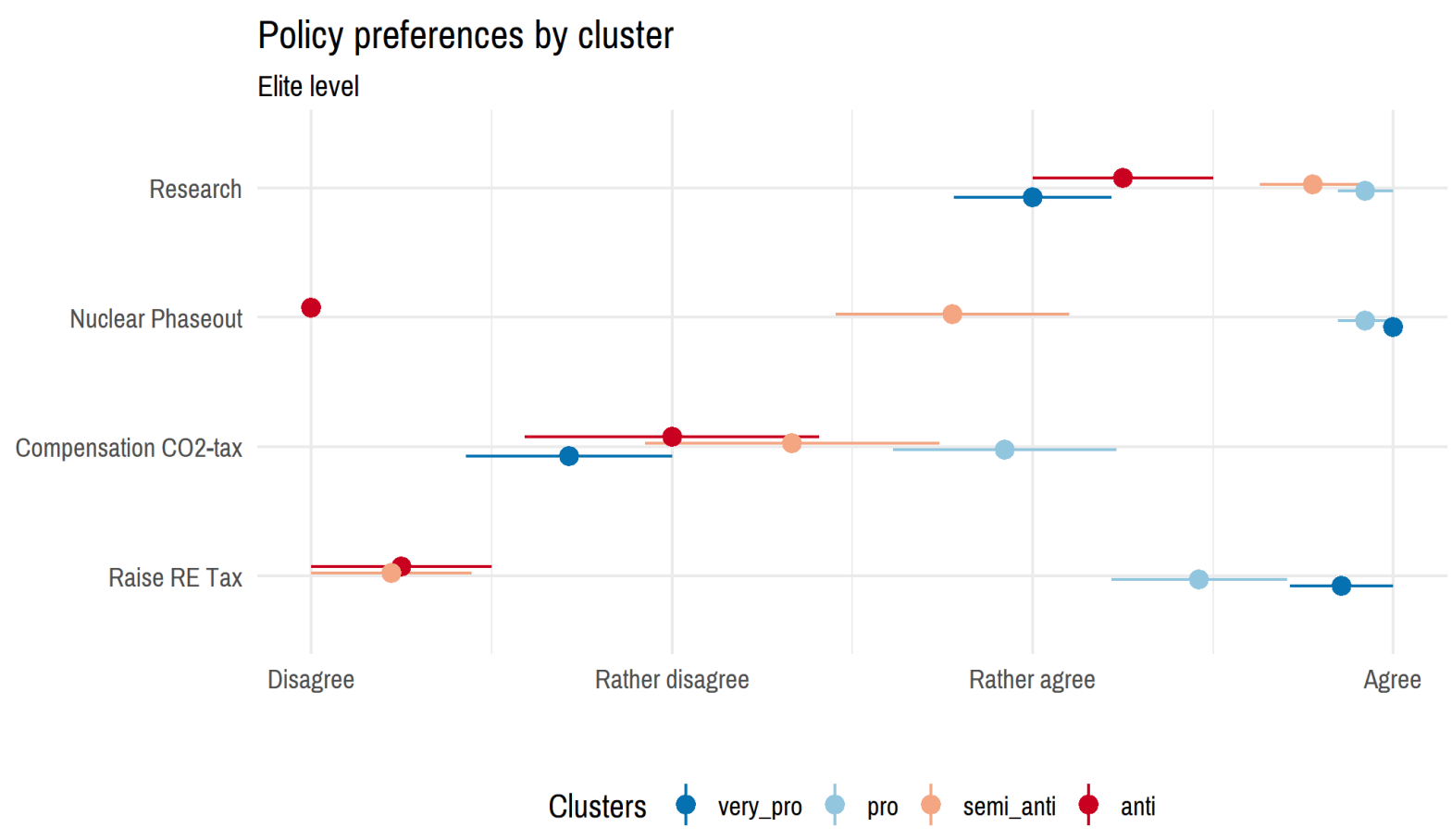

Figure 5: Policy preferences, elite level.

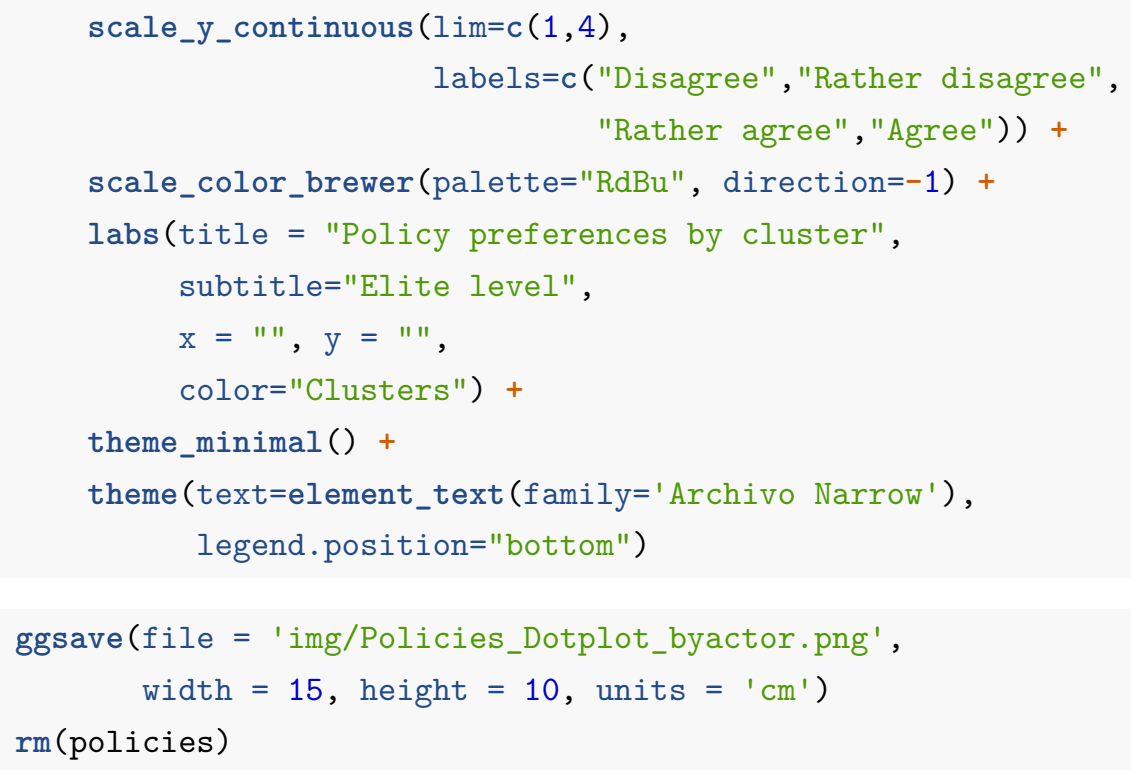




\section{Individual level}

\subsection{Preferences for Energy Strategy 2050}

First, a comparison to the instrument preferences on elite level is done. For this, four variables are evaluated in the same way as for the clusters in the elite analysis. Clustering respondents into similar groups as with the elite was also tested. However, the results remained inconclusive, as the differences in attitudes for individuals compared to parties are smaller and less polarized, therefore not yielding interpretable clusters.

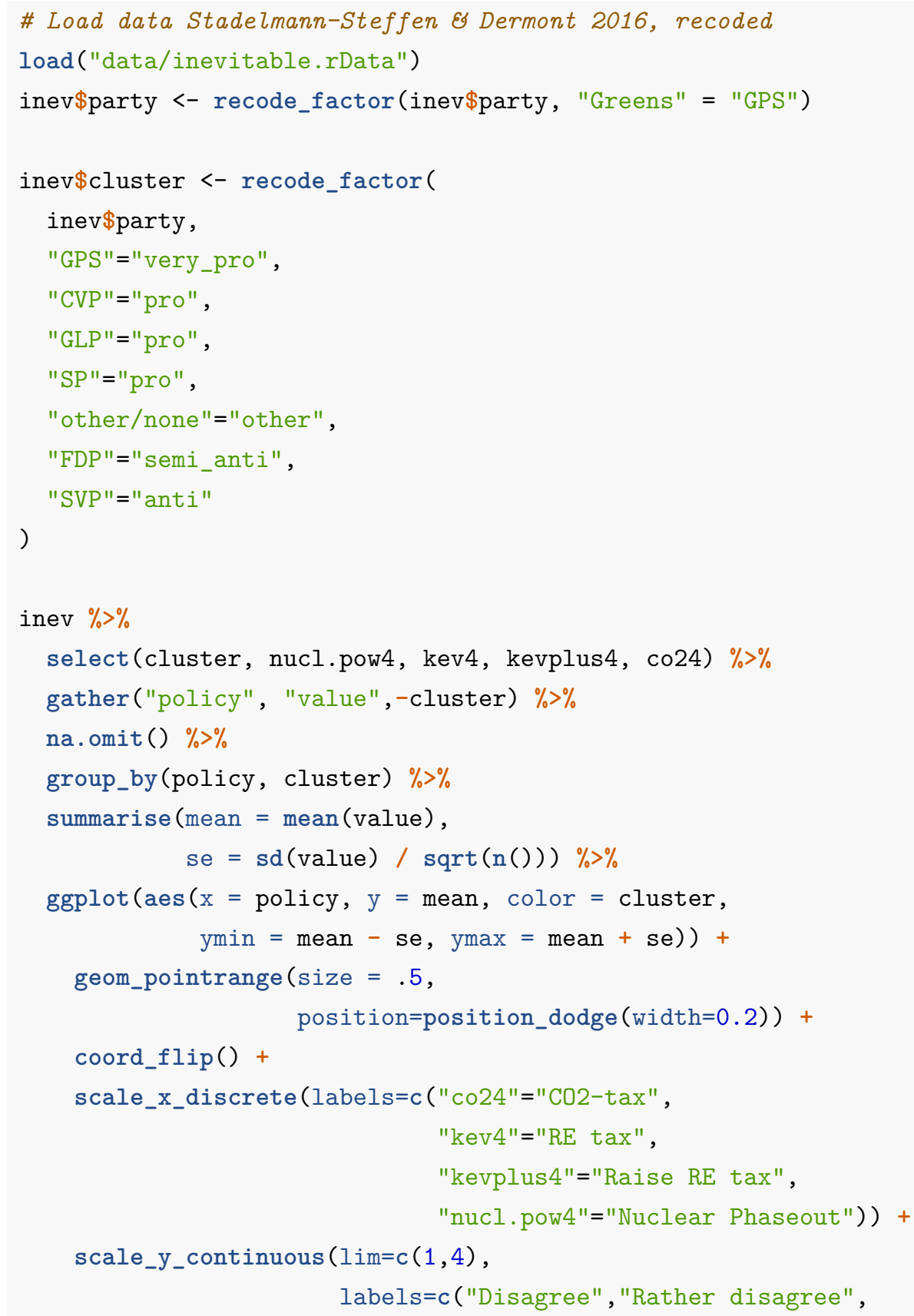




\section{Policy preferences by cluster}

Individual level, grouped into clusters by party preference

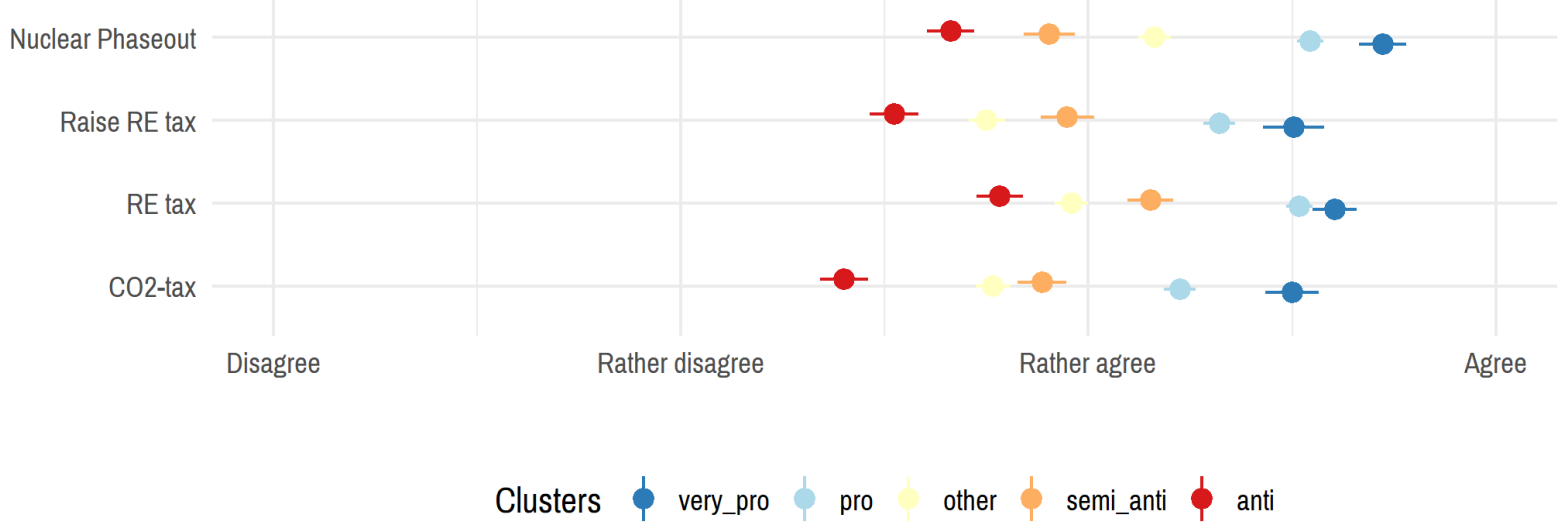

Figure 6: Policy preferences, individual level.

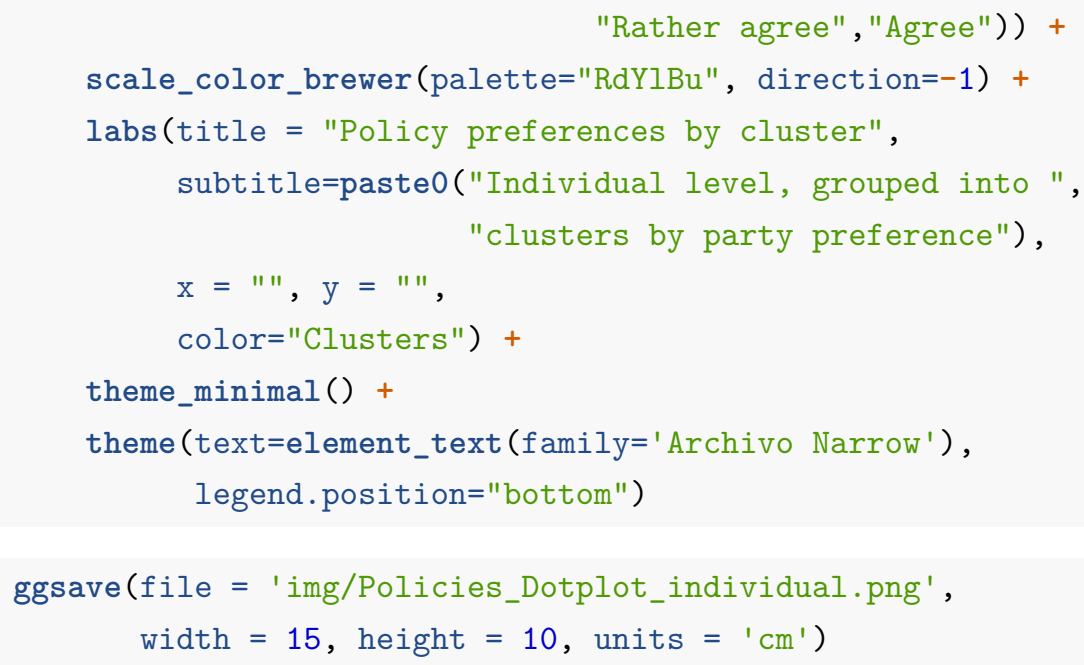

Also, the question arises which energy sources are preferred by the respondents, depending on the party position.

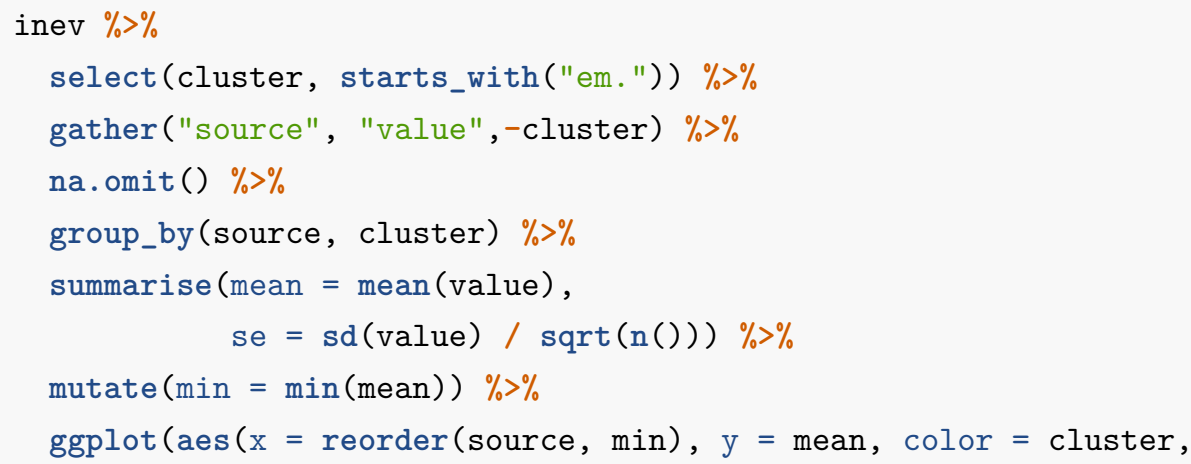




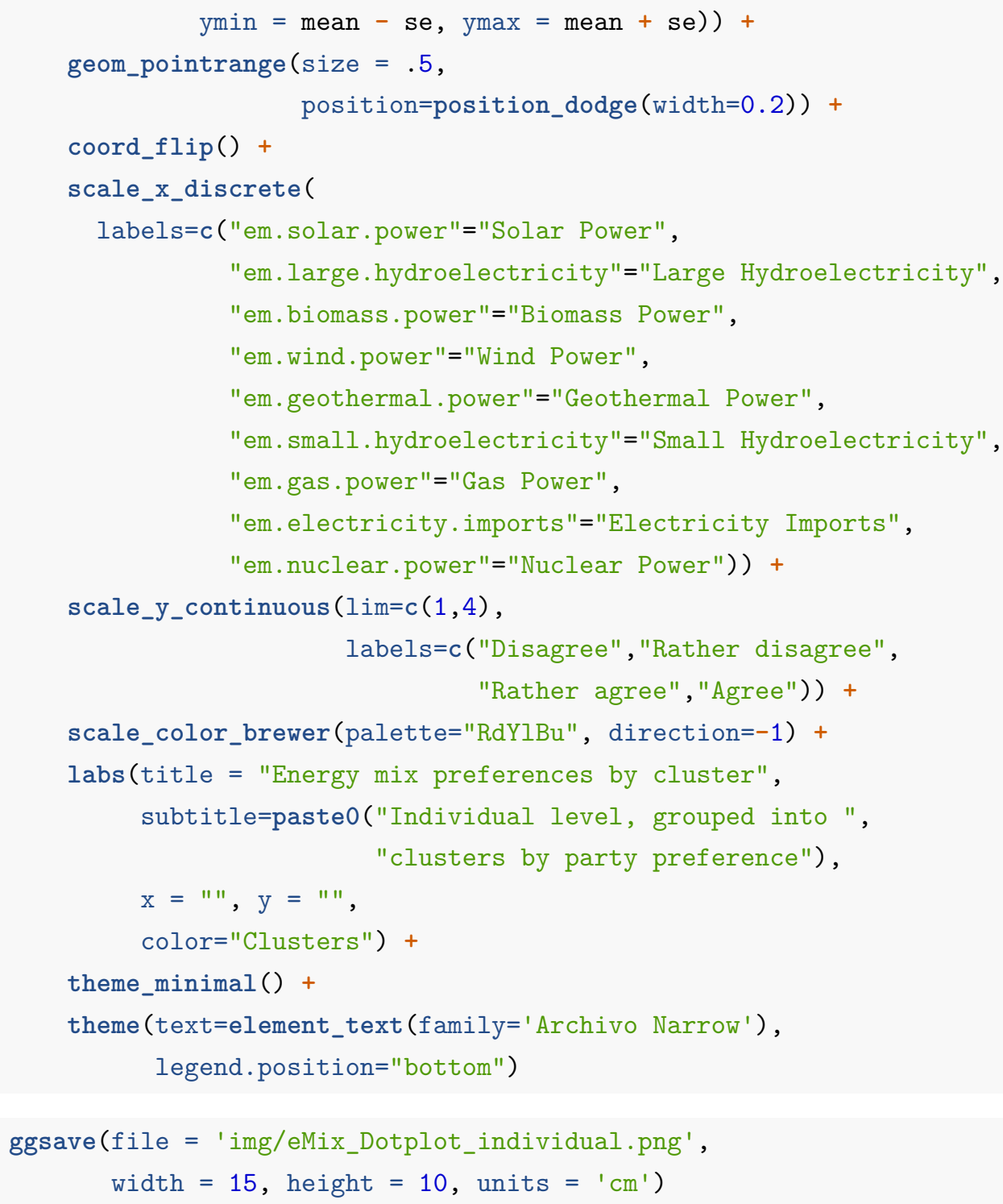

\subsection{Look into further promotional measures}

As those measures are generally defined for the next few years through the 2017 vote on the energy act, a look at how possible policies are supported or opposed by individuals will be the next step.

As dependent variables, we consider seven different policies to promote and the option not to promote energy transitions. The questions were framed for four specific types of renewable energy, namely wind power, solar power, small hydroelectricity and geothermal energy. Each respondent was treated with one energy source, leading to four sub-samples with answers to a specific type of renewable energy, which are combined in the analysis to get to overarching answers on energy transitions. The policies are:

- Tax reductions for operators of renewable energy plants 


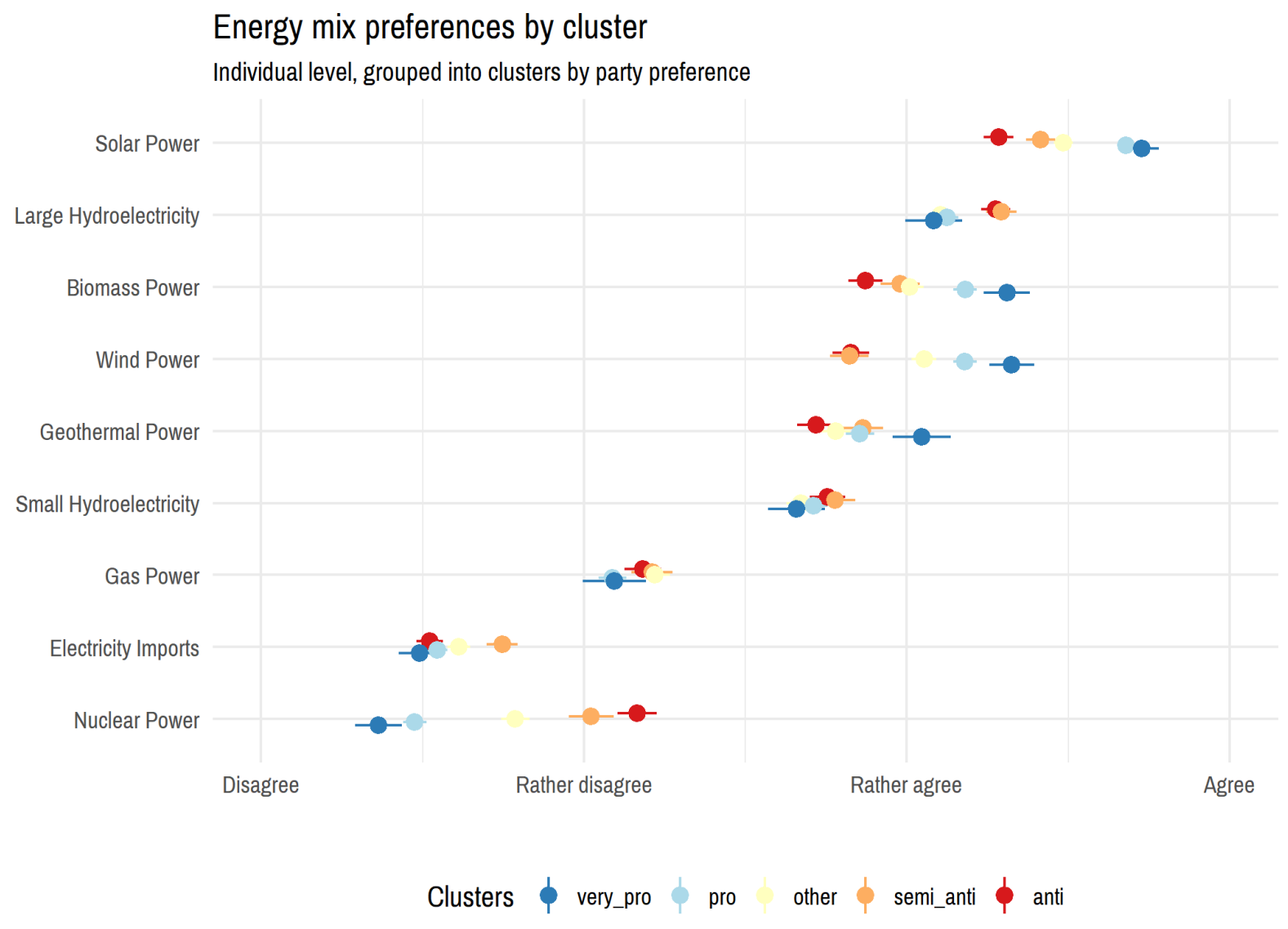

Figure 7: Energy mix preferences, individual level. 
- Subsidies for building renewable energy plants

- Bans on building electricity plants for non-renewable energy sources

- Public tendering to find investors for building renewable energy plants

- Public investments in the production of renewable energy

- Energy companies shall be instructed to build renewable energy plants

- More information, consultation and education for people considering building renewable energy plants

- None of the above, renewable energies should not be promoted

The respondents had the possibility to select all of the options they wanted, excluding combinations of "none" with the others. Furthermore, an option to select "don't know" was provided. The order of the policies was randomized for each individual, excluding the presentation of "none" and "don't know" at the end.

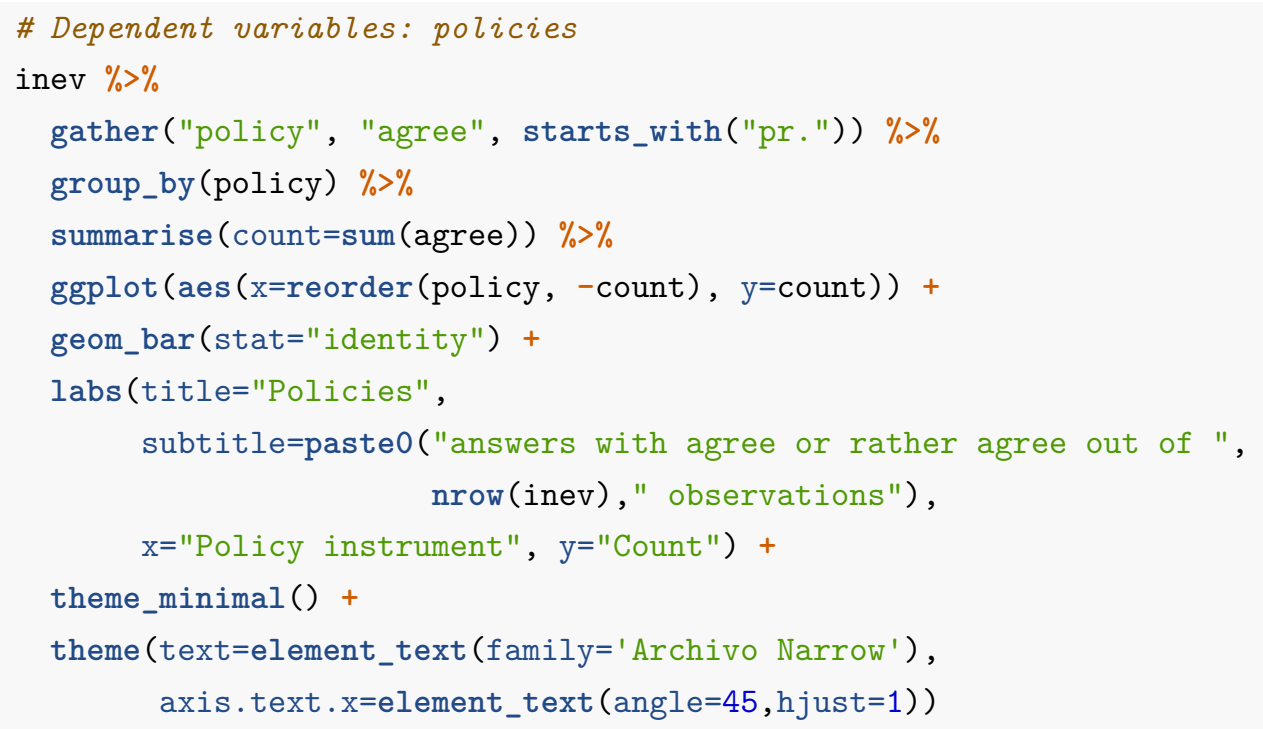

For all models, the main explaining variables are climate change skepticism, general attitudes towards the environment and the political ideology by party preference. We will break up the clusters combining the Social Democrats, the Green Liberals and the Christian Democrats to gain further insights into how their positions might vary.

Climate change is composed from four variables with four answers: agree/rather agree/rather disagree/disagree, whereby agreement with the statements is coded as being skeptic on human-induced climate change:

- climScept.1: I'm unsure if climate change really happens

- climScept.2: Climate change is primarily caused by humans (recoded)

- climScept.3: The consequences of climate change are exaggerated

- climScept.4: Climate change is an excuse to patronize or tax people

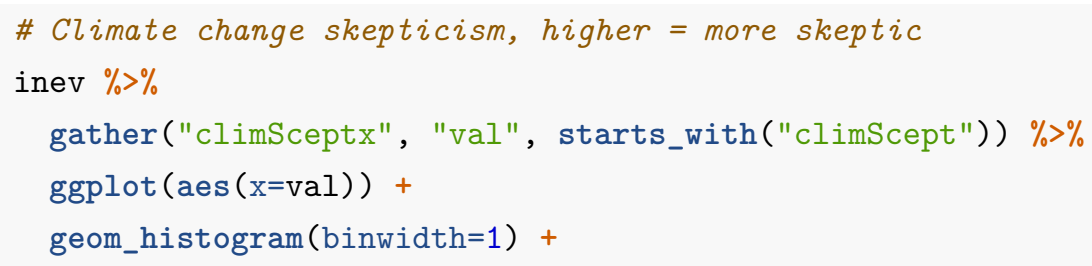




\section{Policies}

answers with agree or rather agree out of 1985 observations

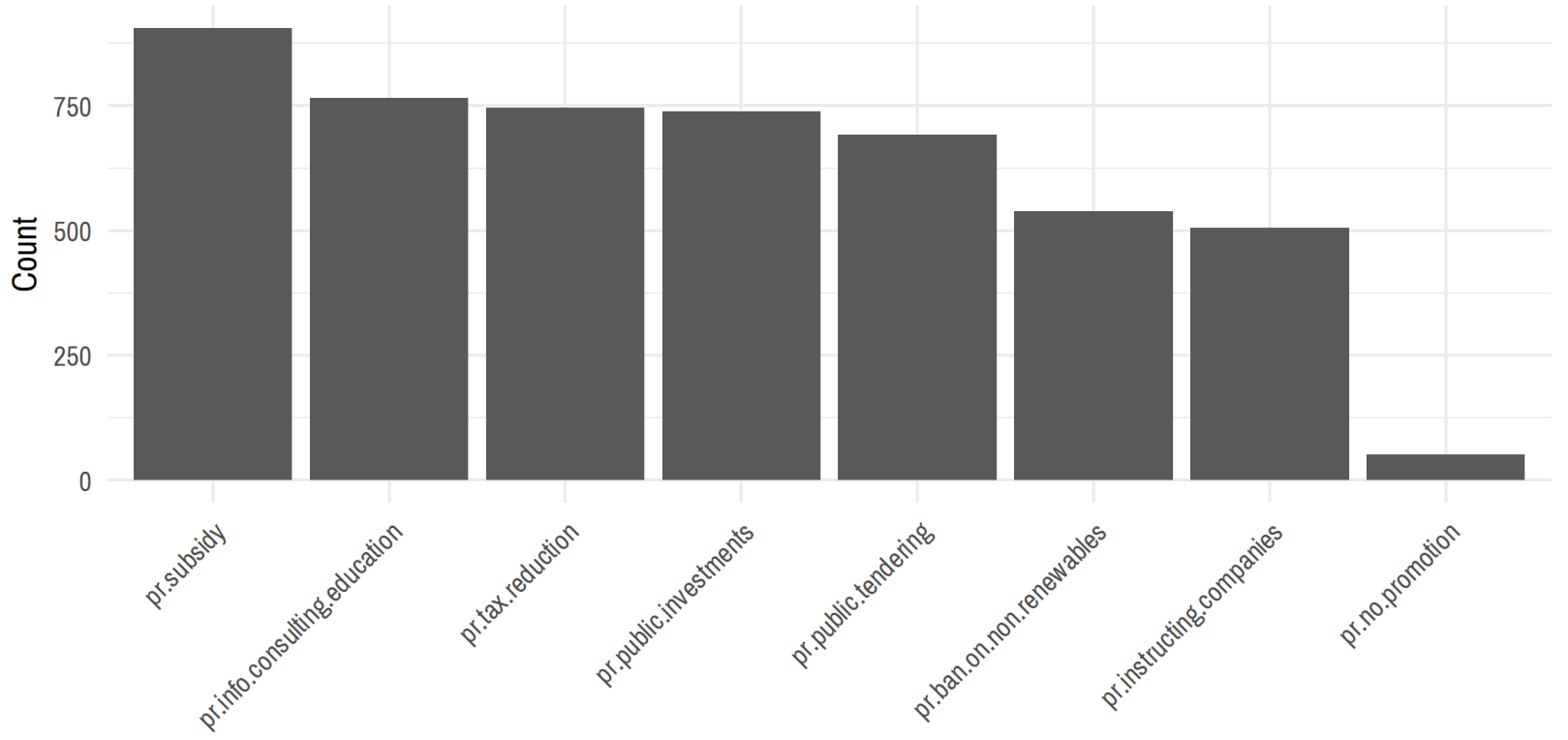

Policy instrument

Figure 8: Dependent variables.

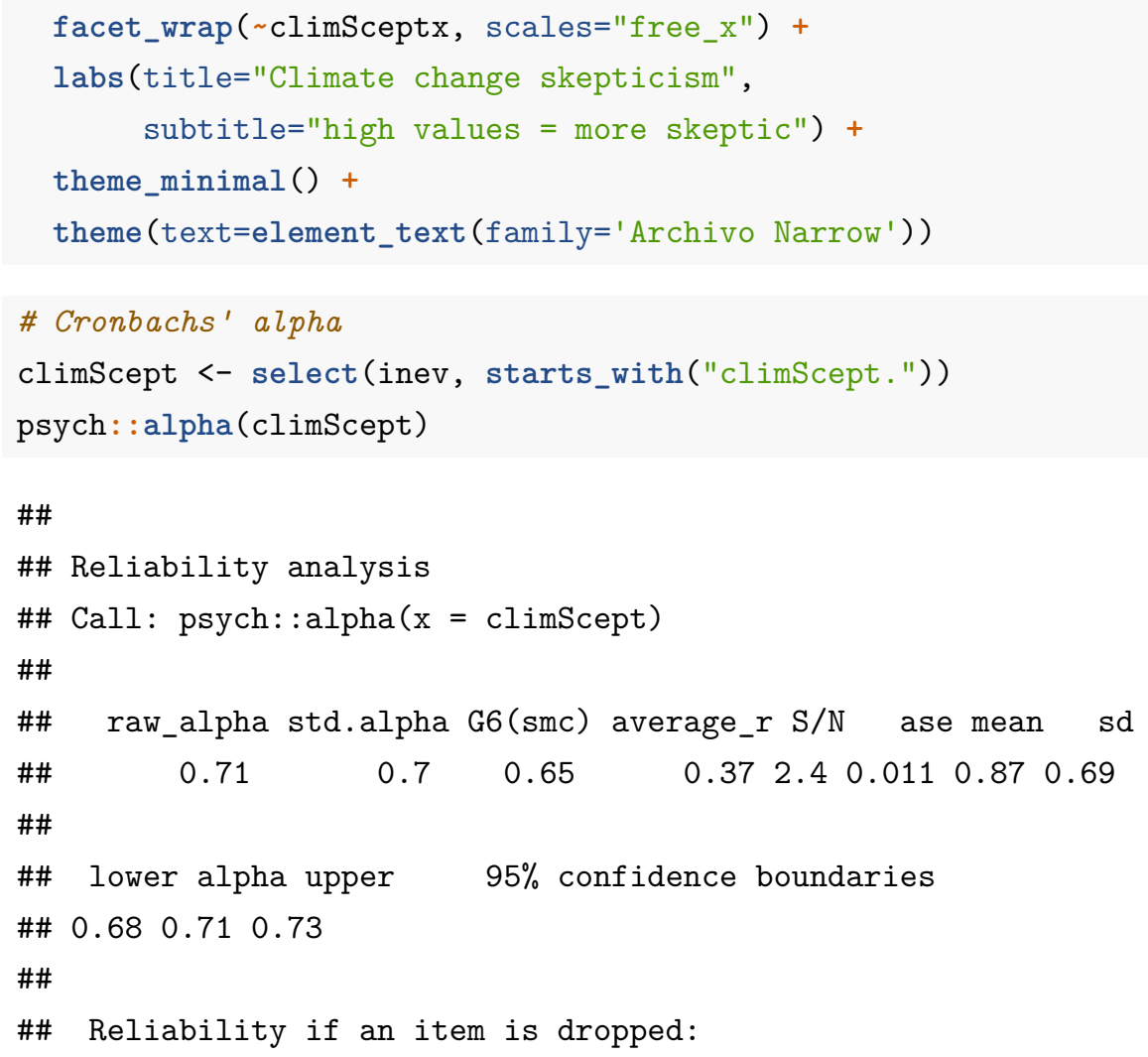


Climate change skepticism

high values $=$ more skeptic

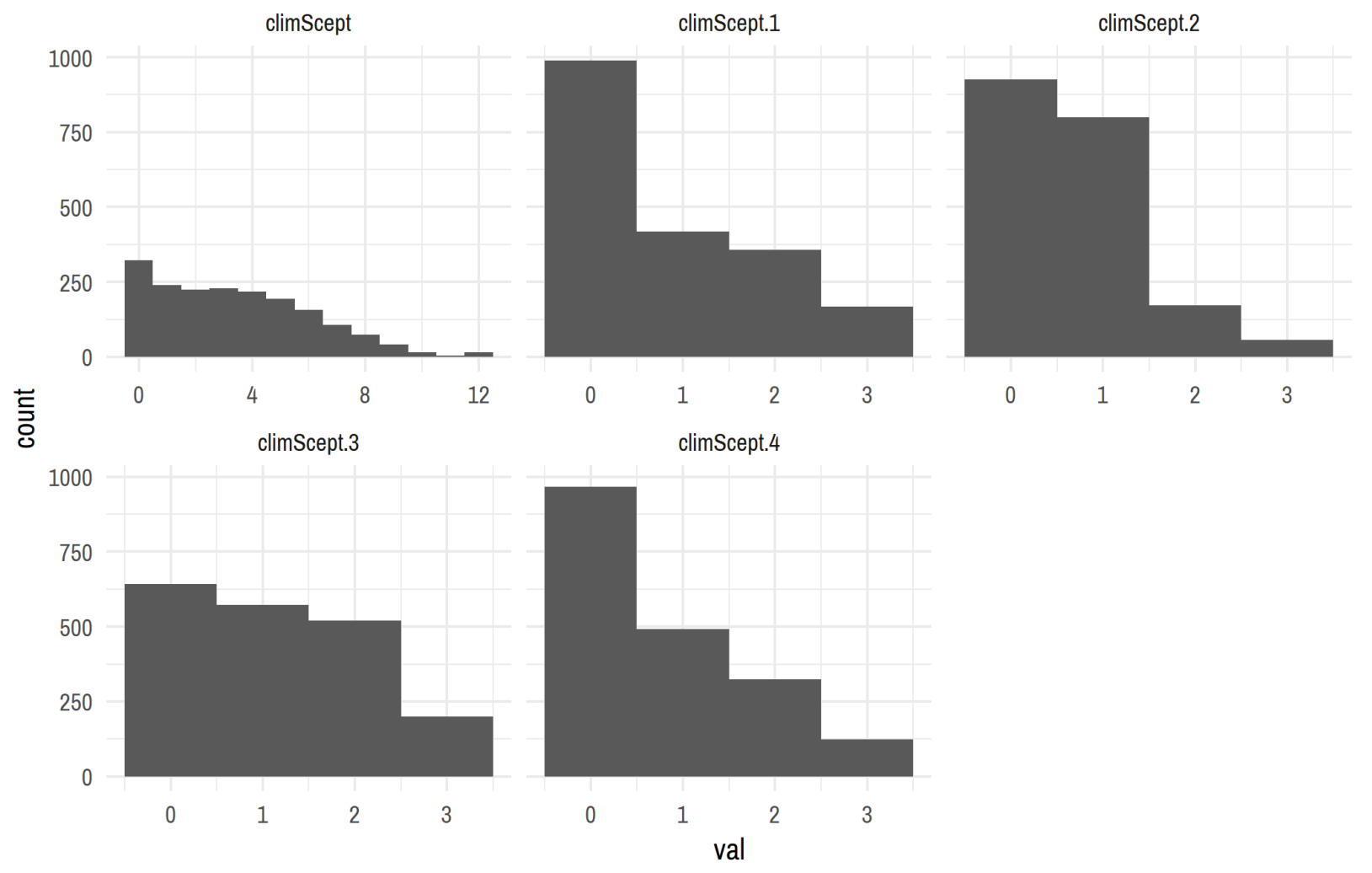

Figure 9: Independent variables. Climate change skepticism. 


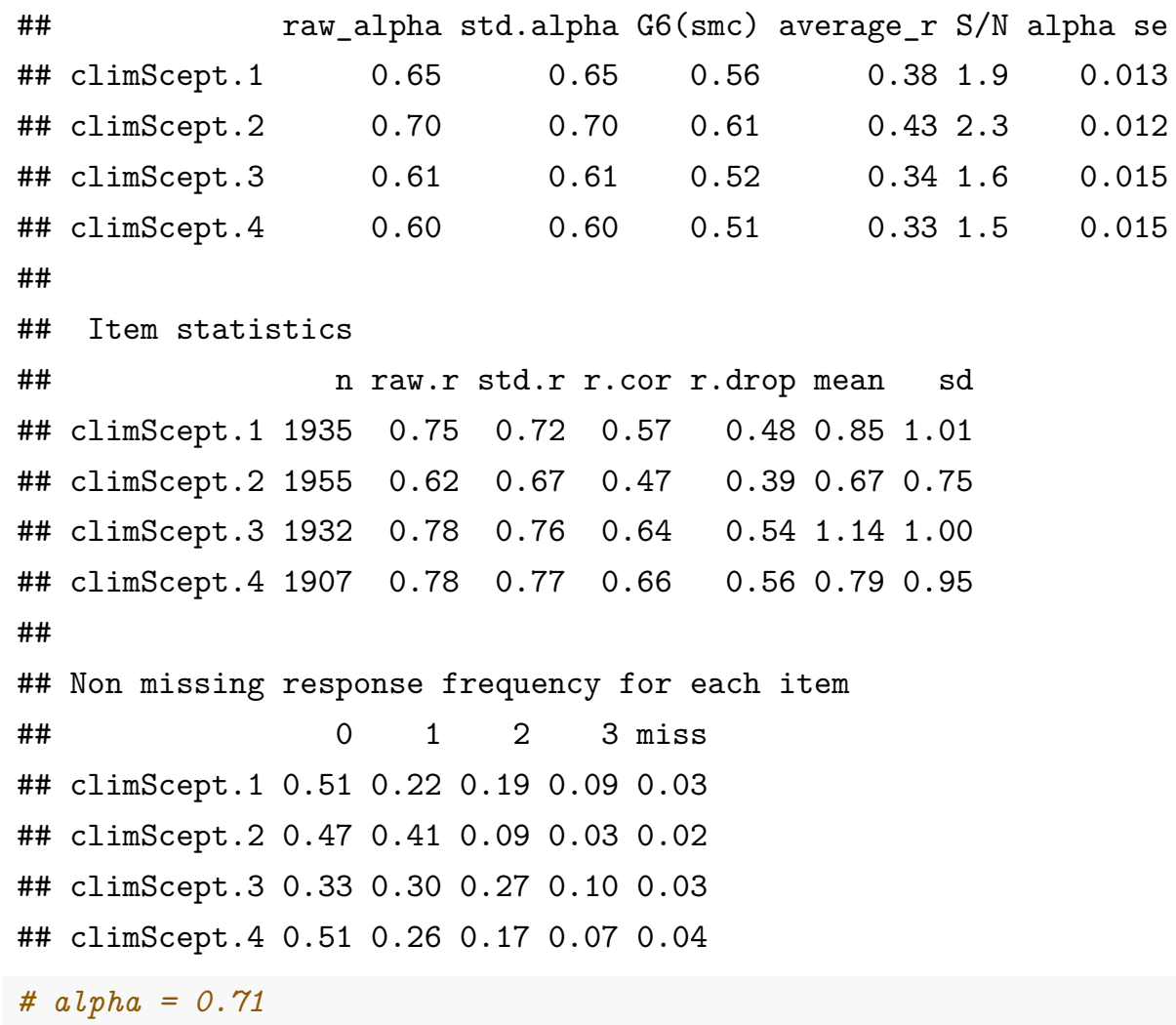

Environmental attitudes are captured with two variables reflecting whether an individual prefers environmental protection over the use of ressources and economic welfare, whereby high values are poled as being more environmental friendly:

- attiEnvir.1: Economic welfare vs. environmental protection

- attiEnvir.2: Use of natural ressources vs. protection of nature and landscape

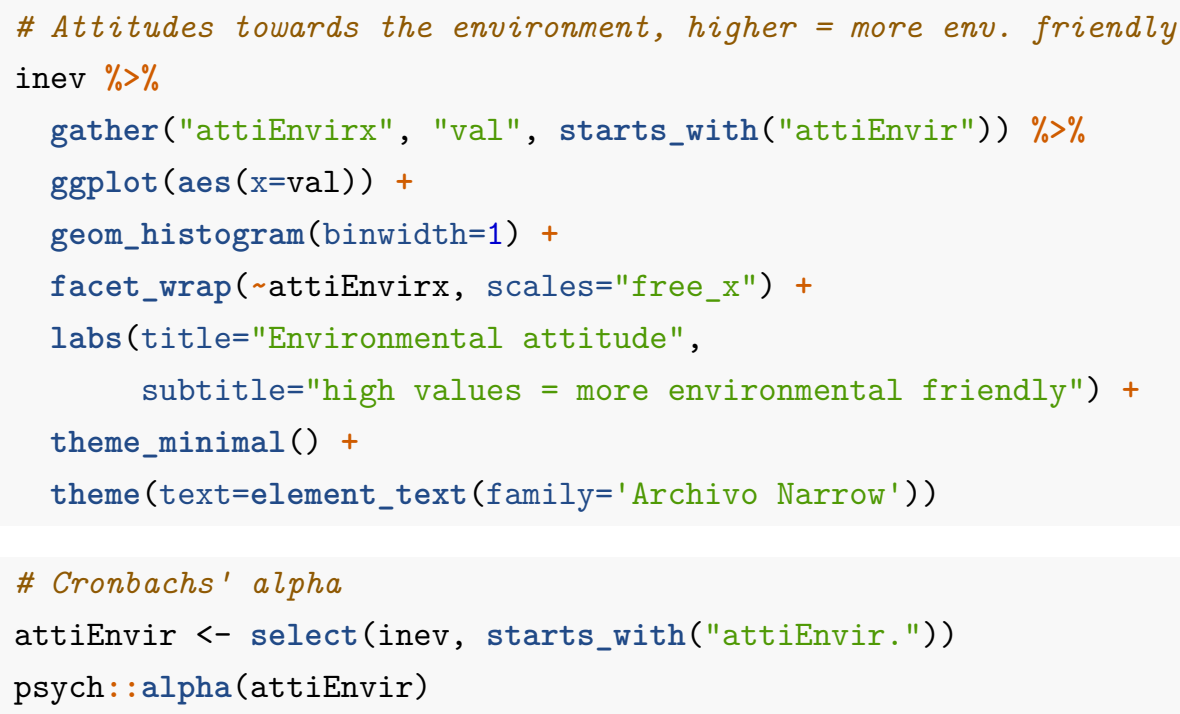




\section{Environmental attitude}

high values $=$ more environmental friendly

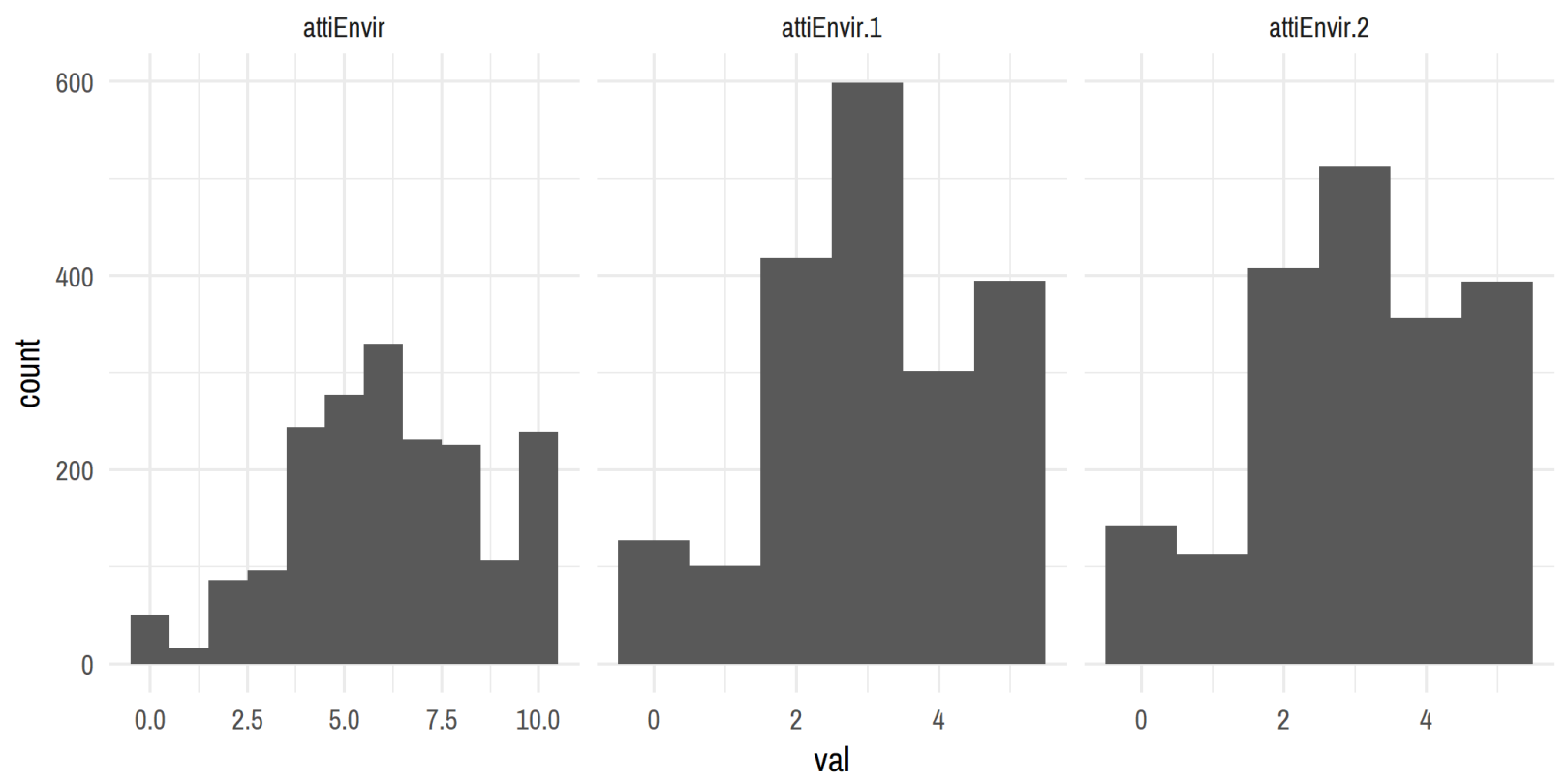

Figure 10: Independent variables. Environmental attitude.

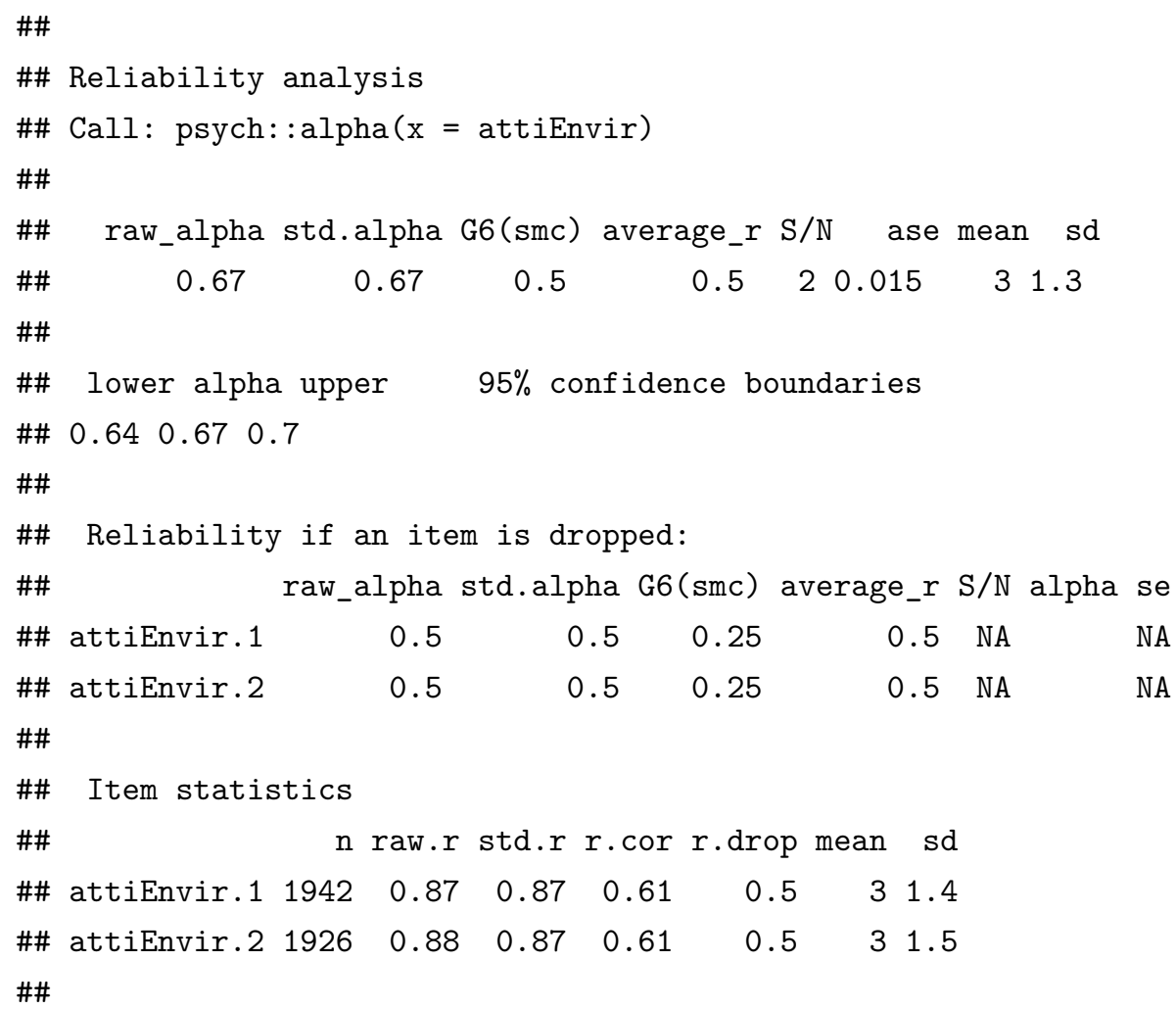




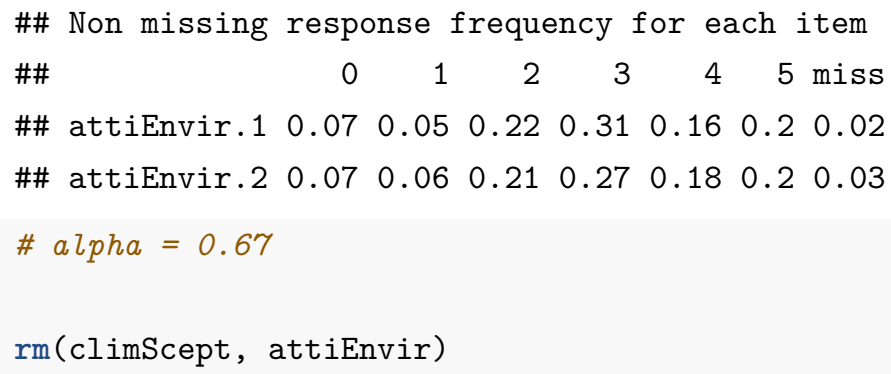

Political ideology or more precisely party preference, lastly, is the party an individual did vote for in the National elections 2015, roughly half a year before the survey was conducted. We consider the four biggest parties and the two green parties.

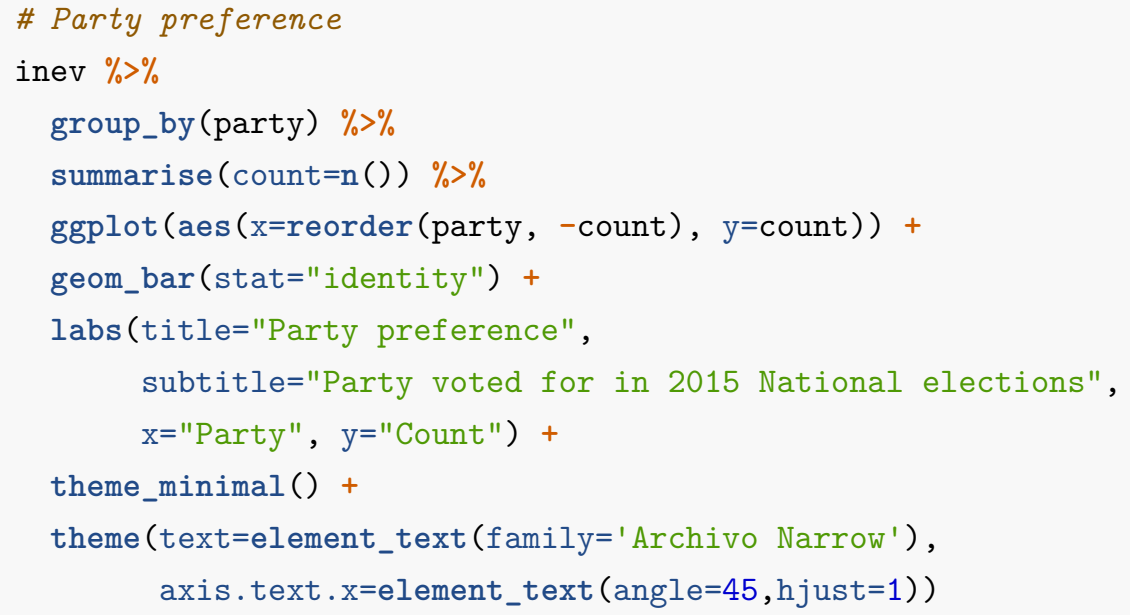

\subsection{Climate change skepticism and clusters}

Before turning to the individual level models, the hypothesis that climate change skepticism is independent of political ideology is tested. Due to the ordered answers in climate change skepticism and the group of clusters, Chi-Squared Tests of Independence are conducted.

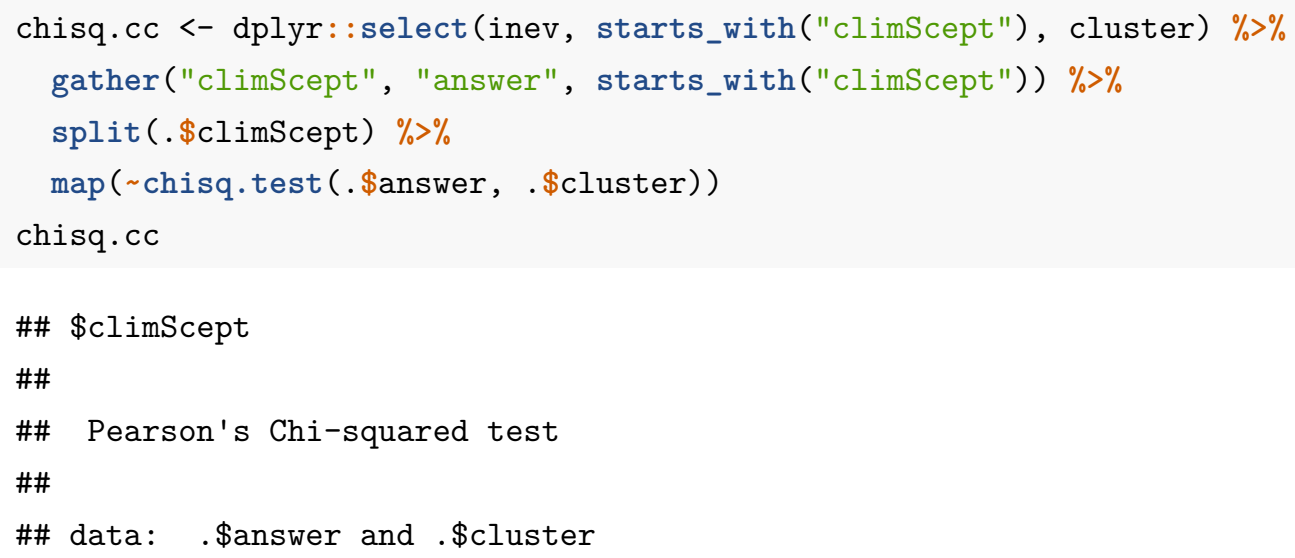




\section{Party preference}

Party voted for in 2015 National elections

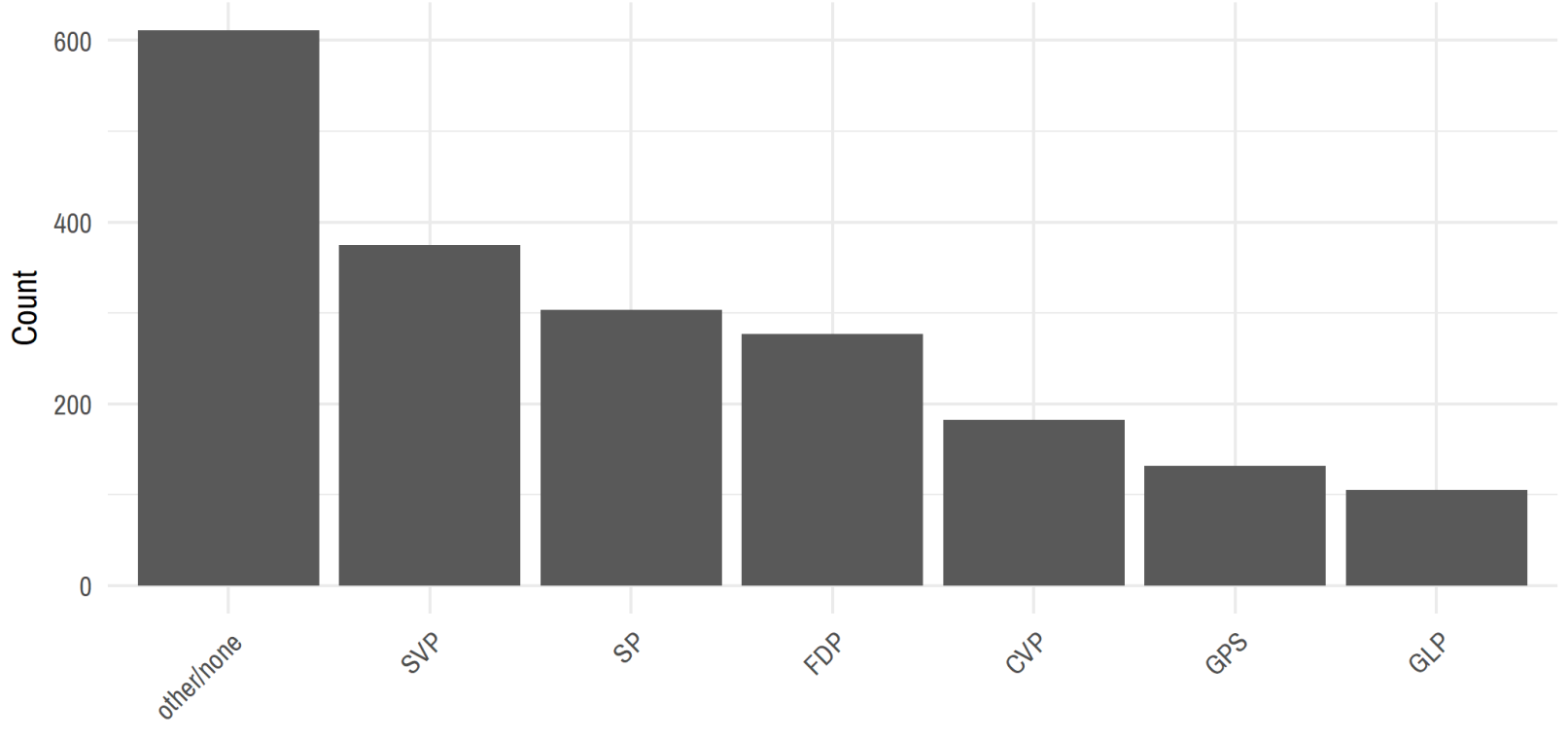

Party

Figure 11: Independent variables. Party preference.

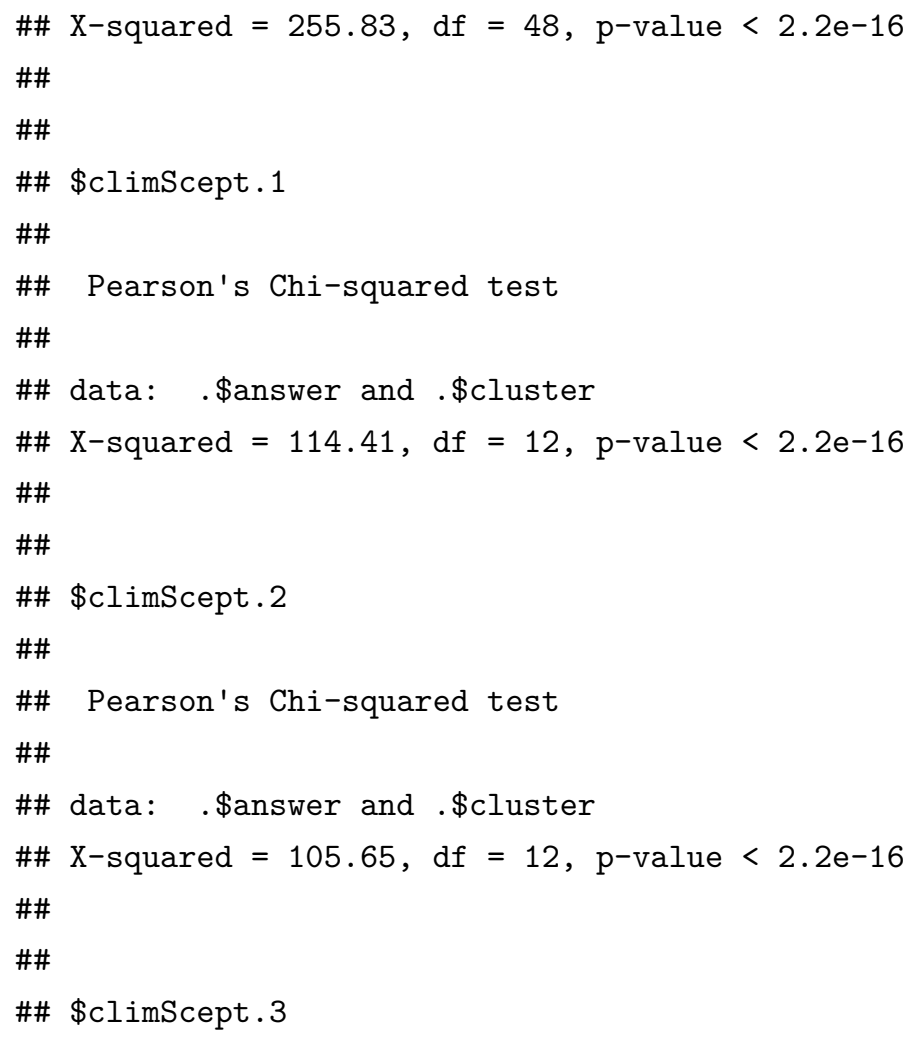




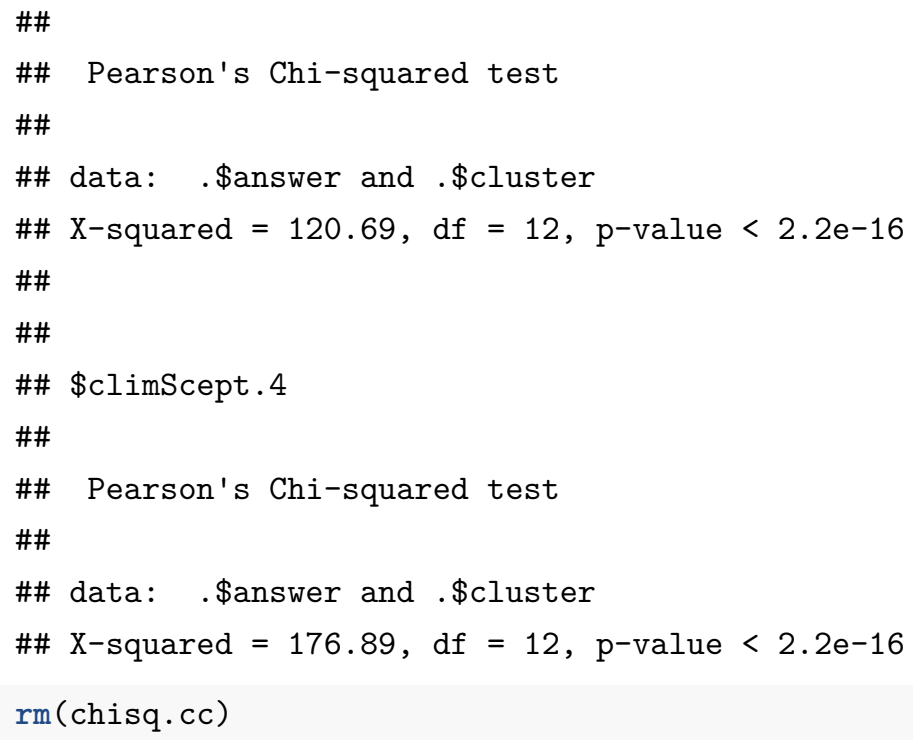

The Chi-Squared tests show that for all four questions independently, as well as for the combined variable representing an overall score of climate change skepticism, the repartition is not independent from the clusters as computed through elite beliefs. This said, the hypothesis that climate change skepticism is independent from the political parties represented by those clusters can be rejected.

\subsection{Individual level models}

Having established that political ideology and climate change skepticism are not independent from each other, the question arises if those two variables lead to distinct perspectives on which policies are preferred or supported for the promotion of renewable energy sources. Moreover, the question arises whether or not climate change skepticisim is used as a reason to oppose energy transitions.

For this, structural equation modeling (SEM) is appropriate. First, they allow to construct latent variables such as opposition to renewable energy promotion or climate change skepticism based on several observed items. Second, path analysis enables to estimate both direct and indirect paths of influence of one concept on another. SEM therefore facilitate to investigate how political ideology and climate change skepticism are related with each other and with opposition. Figure 12 shows the setup of the model.

Three latent variables (ellipses) are estimated:

- Opposition towards the promotion of energy transitions, computed through seven observed variables representing the described policies (excluding the item 'no promotion'),

- Climate Change Skepticism, representing the four variables on opinion towards climate change,

- and Environmental Attitudes, based on the two variables on preferences for the environment.

As manifest variable, political ideology in form of political party preference is considered. With those four variables, three regressions will be estimated, each explaining a latent variable. In the regressions, gender, age, education and income will be included as control variables. 


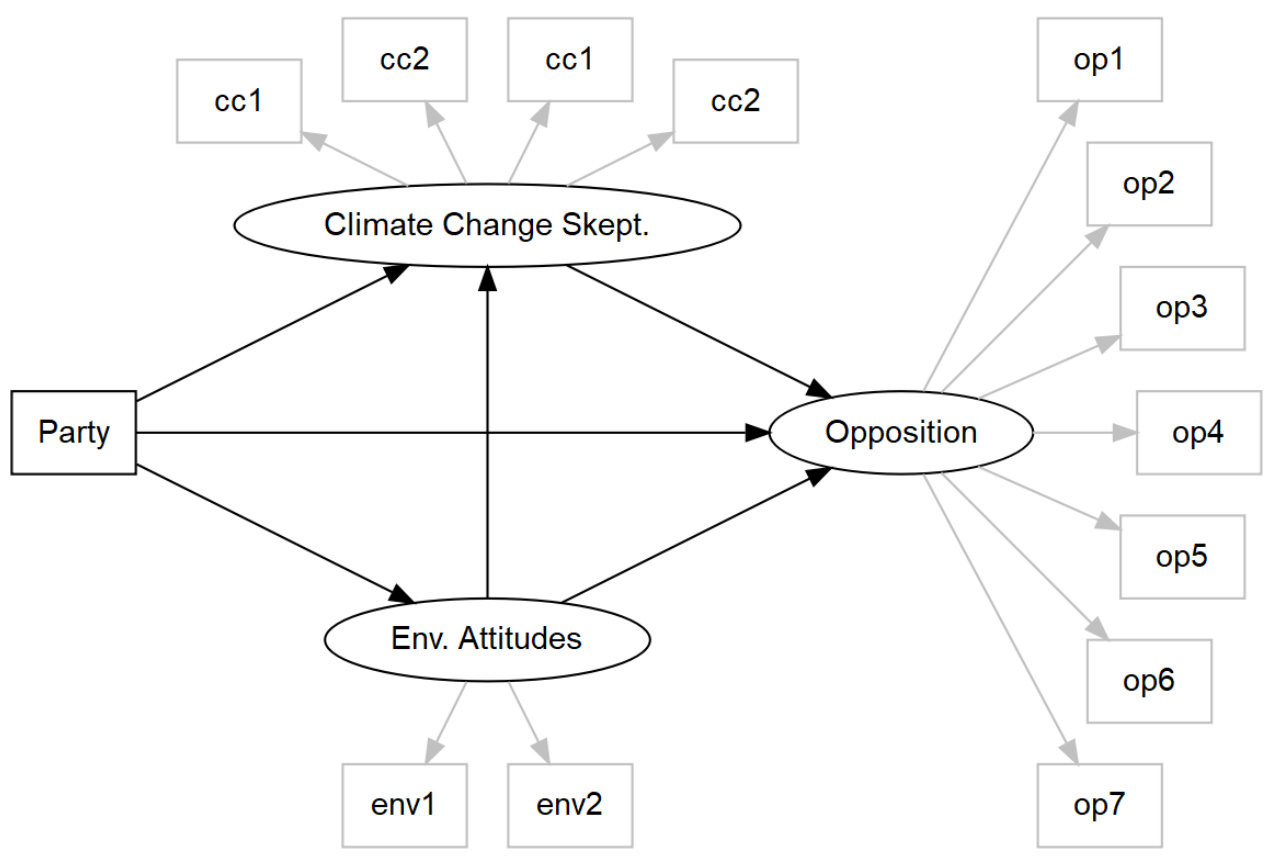

Figure 12: Path model.

\subsubsection{Structural equation modeling}

In order to be able to interpret the results more straightforward, a few operationalizations will be changed. First, instead of looking at support for policies, we recode the variables as representing opposition (1=opposition). Second, we create dummy variables for party, education and income.

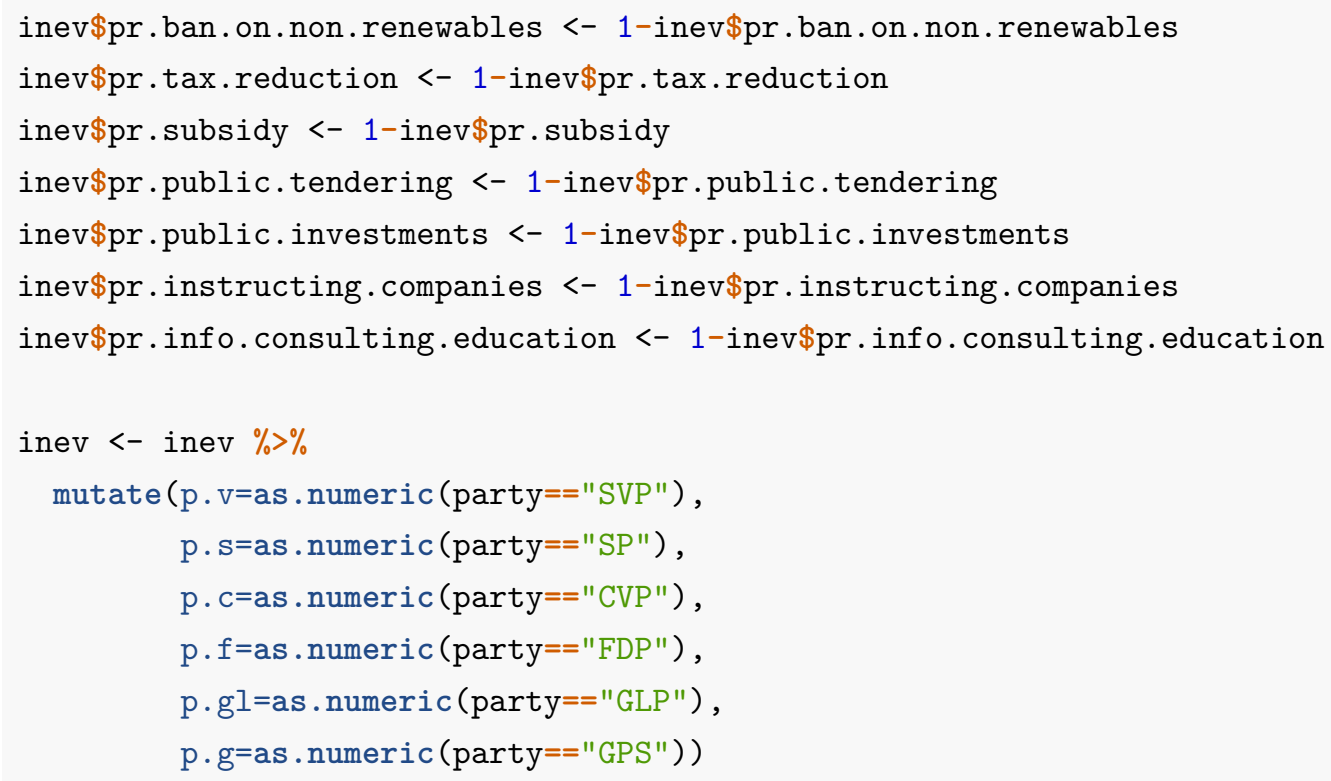




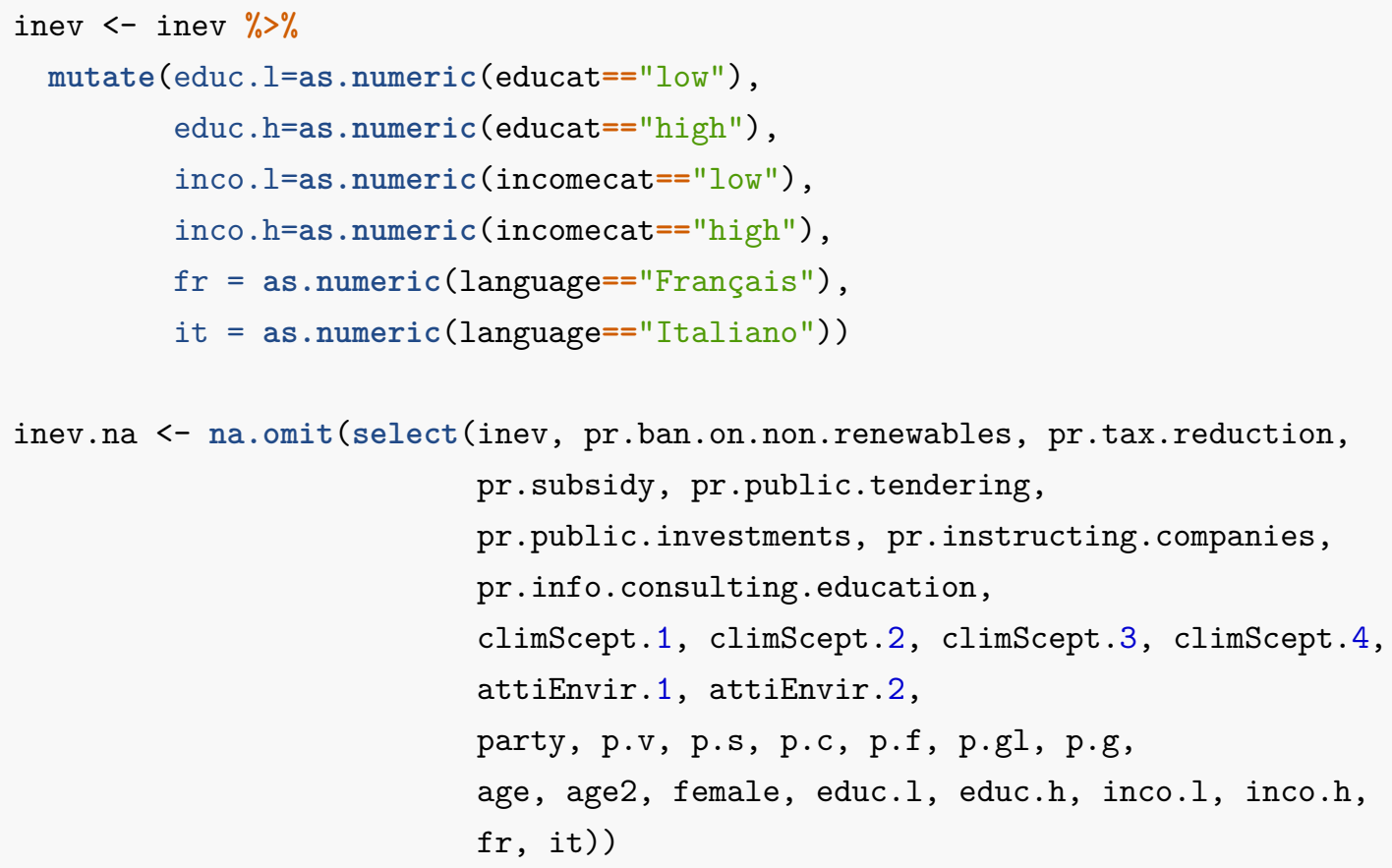

For estimation in the R-package lavaan, the following code describes the SEM. Notably, op is the latent variable representing opposition towards the promotion of energy transitions, $\mathrm{cc}$ is the latent variable representing climate change skepticism, and env is the latent variable representing attitudes towards the environment. Three regression models estimate those three latent variables with the main explaining variable of political ideology, included as dummies for party preference.

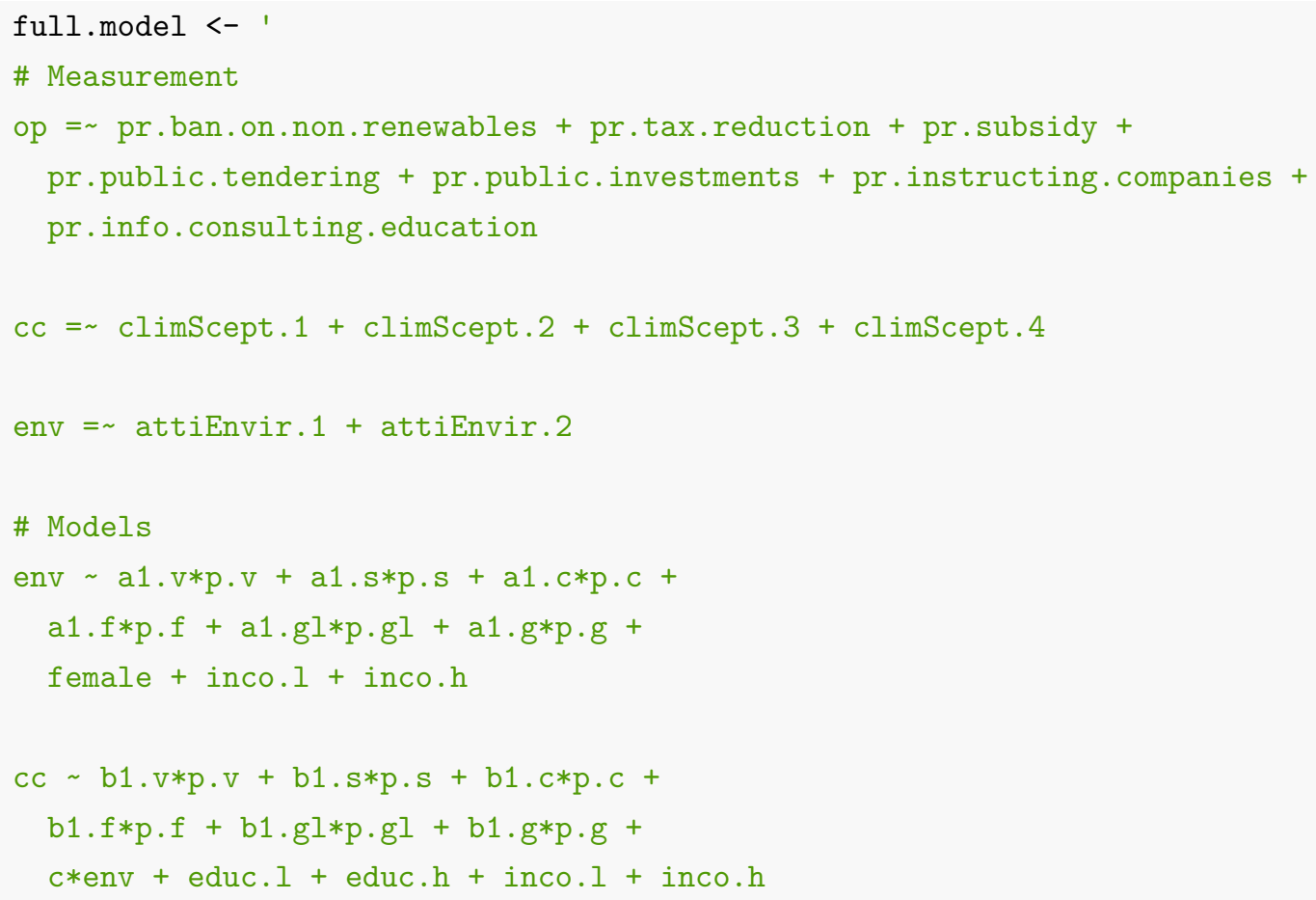




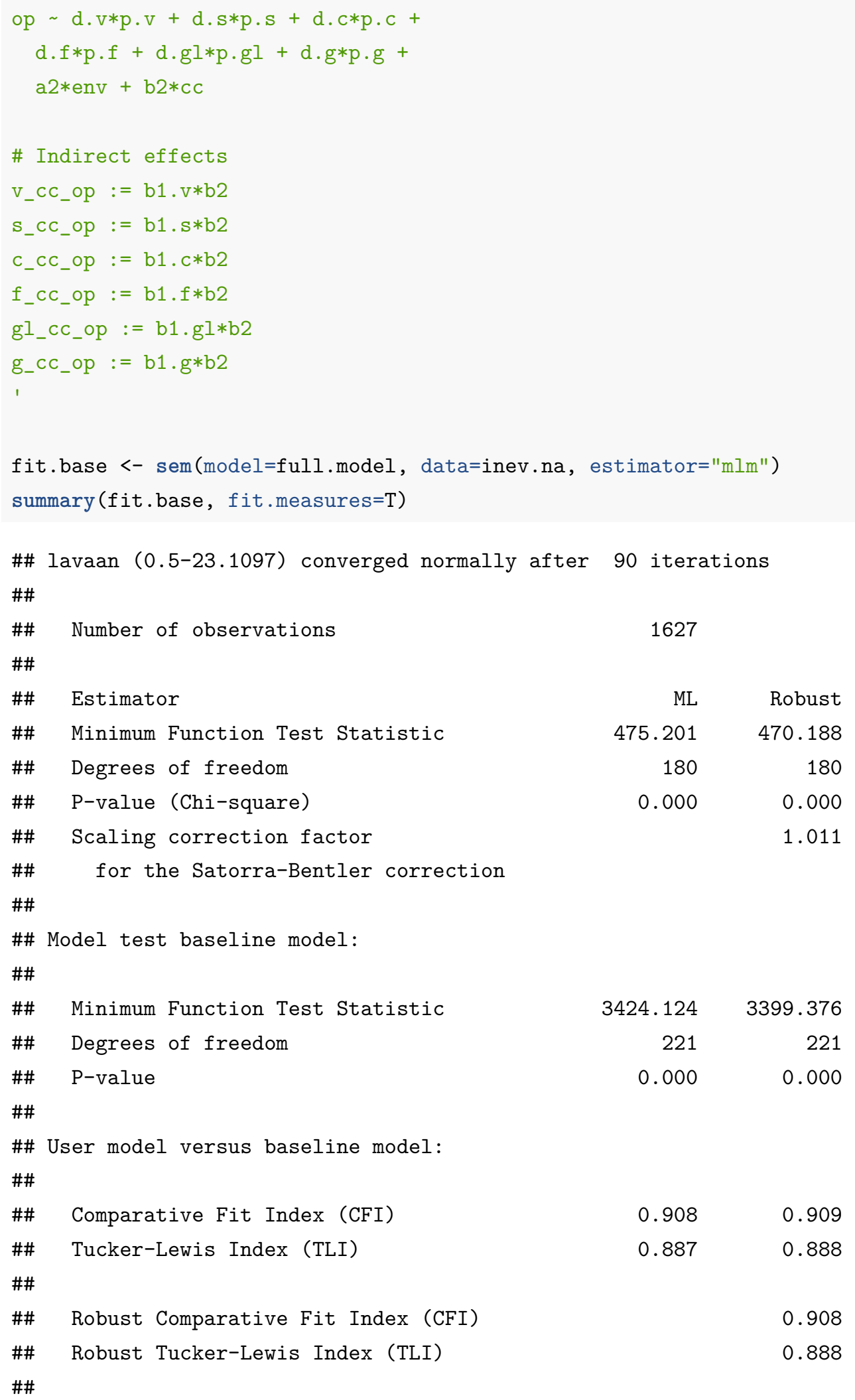




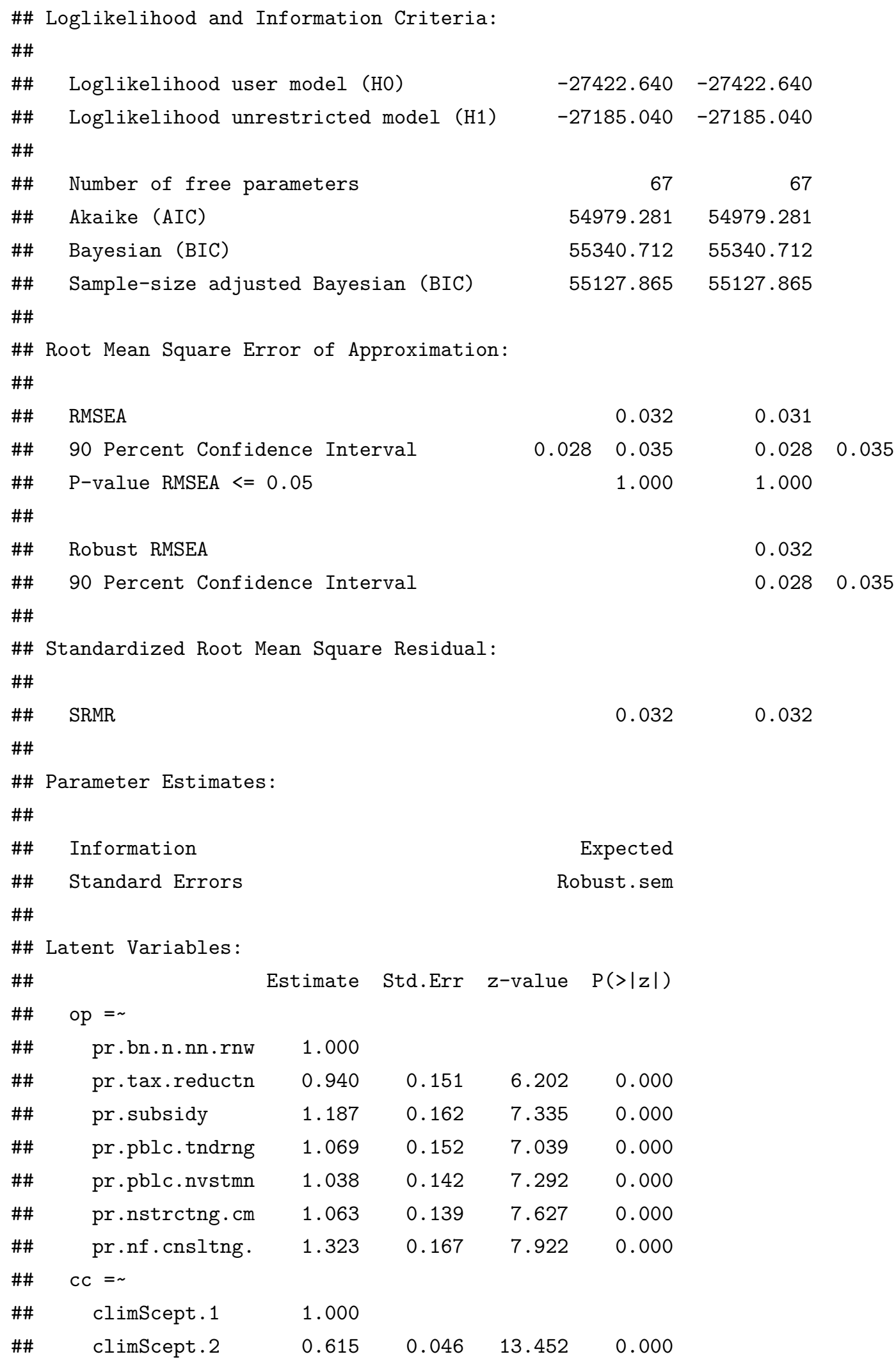




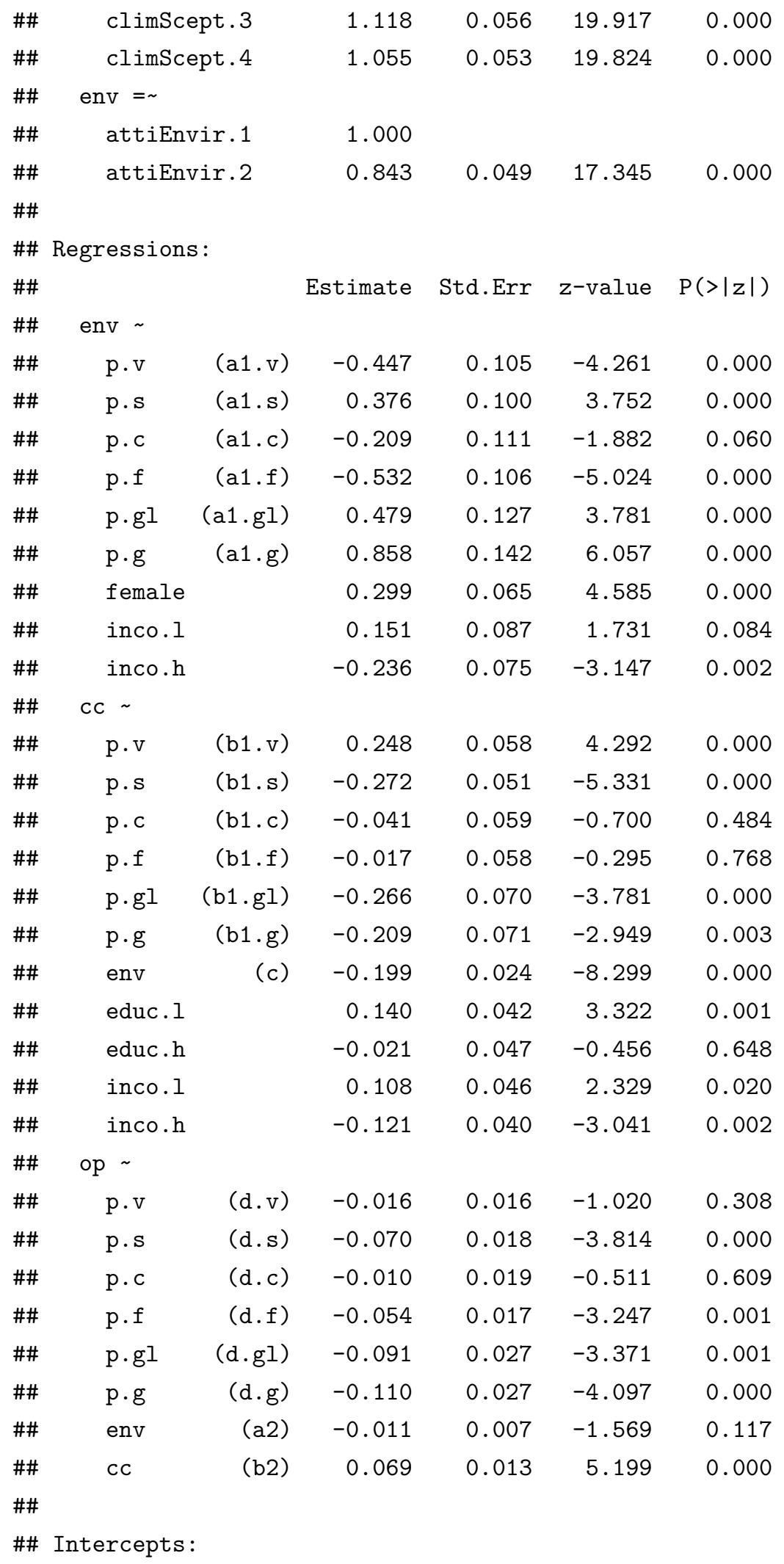




\begin{tabular}{|c|c|c|c|c|c|}
\hline \#\# & & Estimate & Std.Err & $z$-value & $P(>|z|)$ \\
\hline$\# \#$ & .pr.bn.n.nn.rnw & 0.748 & 0.015 & 51.308 & 0.000 \\
\hline \#\# & .pr.tax.reductn & 0.643 & 0.015 & 41.568 & 0.000 \\
\hline \#\# & .pr.subsidy & 0.570 & 0.017 & 32.775 & 0.000 \\
\hline \#\# & .pr.pblc.tndrng & 0.677 & 0.016 & 42.520 & 0.000 \\
\hline \#\# & .pr.pblc.nvstmn & 0.646 & 0.016 & 40.892 & 0.000 \\
\hline \#\# & .pr.nstrctng.cm & 0.773 & 0.015 & 52.916 & 0.000 \\
\hline \#\# & .pr.nf.cnsltng. & 0.644 & 0.018 & 36.747 & 0.000 \\
\hline \#\# & .climScept.1 & 0.822 & 0.051 & 15.990 & 0.000 \\
\hline \#\# & .climScept.2 & 0.670 & 0.033 & 20.075 & 0.000 \\
\hline \#\# &. climScept. 3 & 1.101 & 0.056 & 19.529 & 0.000 \\
\hline$\# \#$ & .climScept. 4 & 0.773 & 0.054 & 14.438 & 0.000 \\
\hline$\# \#$ & attiEnvir.1 & 2.999 & 0.081 & 36.929 & 0.000 \\
\hline \#\# & .attiEnvir.2 & 2.980 & 0.071 & 42.186 & 0.000 \\
\hline \#\# &.$o p$ & 0.000 & & & \\
\hline \#\# &.$c c$ & 0.000 & & & \\
\hline \#\# &.$e n v$ & 0.000 & & & \\
\hline \multicolumn{6}{|l|}{ \#\# } \\
\hline \multicolumn{6}{|c|}{ \#\# Variances: } \\
\hline \#\# & & Estimate & Std.Err & z-value & $P(>|z|)$ \\
\hline \#\# & .pr.bn.n.nn.rnw & 0.184 & 0.006 & 31.646 & 0.000 \\
\hline \#\# & .pr.tax.reductn & 0.219 & 0.005 & 44.508 & 0.000 \\
\hline \#\# & .pr.subsidy & 0.219 & 0.005 & 40.271 & 0.000 \\
\hline \#\# & .pr.pblc.tndrng & 0.206 & 0.005 & 38.221 & 0.000 \\
\hline \#\# & .pr.pblc.nvstmn & 0.215 & 0.005 & 41.130 & 0.000 \\
\hline \#\# & .pr.nstrctng.cm & 0.171 & 0.006 & 28.593 & 0.000 \\
\hline \#\# & .pr.nf.cnsltng. & 0.203 & 0.006 & 32.967 & 0.000 \\
\hline \#\# &.$c l i m S c e p t .1$ & 0.625 & 0.037 & 16.744 & 0.000 \\
\hline \#\# & .climScept.2 & 0.423 & 0.019 & 22.692 & 0.000 \\
\hline$\# \#$ & .climScept.3 & 0.499 & 0.032 & 15.386 & 0.000 \\
\hline \#\# &. climScept.4 & 0.434 & 0.026 & 16.543 & 0.000 \\
\hline \#\# & attiEnvir.1 & 0.655 & 0.079 & 8.282 & 0.000 \\
\hline$\# \#$ & attiEnvir.2 & 1.131 & 0.075 & 15.081 & 0.000 \\
\hline \#\# &.$o p$ & 0.017 & 0.004 & 4.799 & 0.000 \\
\hline$\# \#$ &.$c c$ & 0.263 & 0.025 & 10.651 & 0.000 \\
\hline \#\# & .env & 1.030 & 0.086 & 11.949 & 0.000 \\
\hline \multicolumn{6}{|l|}{ \#\# } \\
\hline \multicolumn{6}{|c|}{ \#\# Defined Parameters: } \\
\hline \#\# & & Estimate & Std.Err & z-value & $P(>|z|)$ \\
\hline \#\# & $v_{-} c_{-} c_{p}$ & 0.017 & 0.005 & 3.339 & 0.001 \\
\hline \#\# & $s_{-} c c_{-} o p$ & -0.019 & 0.005 & -3.919 & 0.000 \\
\hline
\end{tabular}




$\begin{array}{llllll}\# \# & \text { c_cc_op } & -0.003 & 0.004 & -0.694 & 0.488 \\ \# \# & \text { f_cc_op } & -0.001 & 0.004 & -0.295 & 0.768 \\ \# \# & \text { gl_cc_op } & -0.018 & 0.006 & -3.154 & 0.002 \\ \# \# & \text { g_cc_op } & -0.014 & 0.006 & -2.558 & 0.011\end{array}$

In general, further models with control variables exhibited no added information compared to the presented model. Notably, the demographic control variables do not have a direct effect on opposition itself, highlighting how opposition is a concept largely influenced by political and environmental atittudes and beliefs, which are themselves subjected to demographic influence.

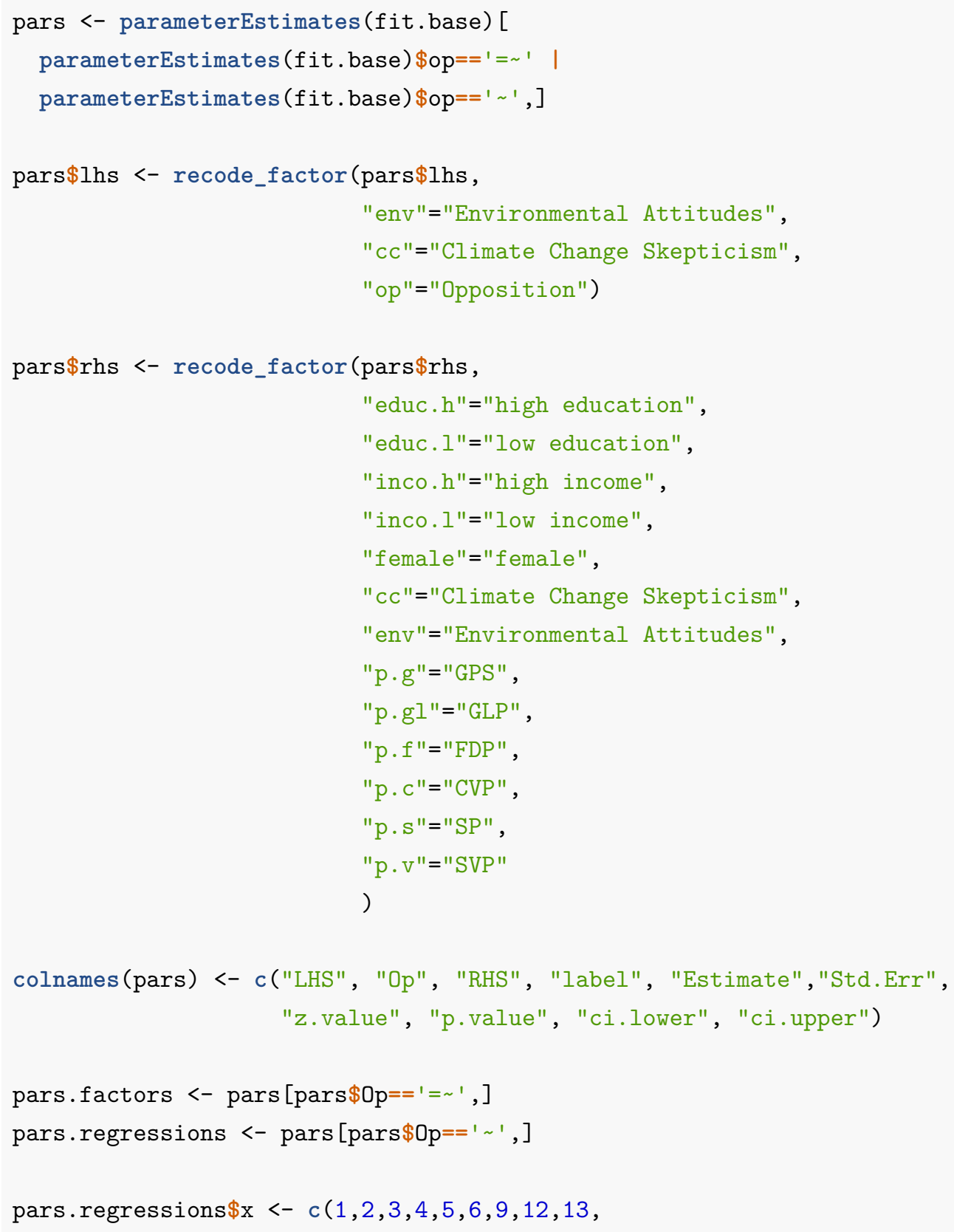




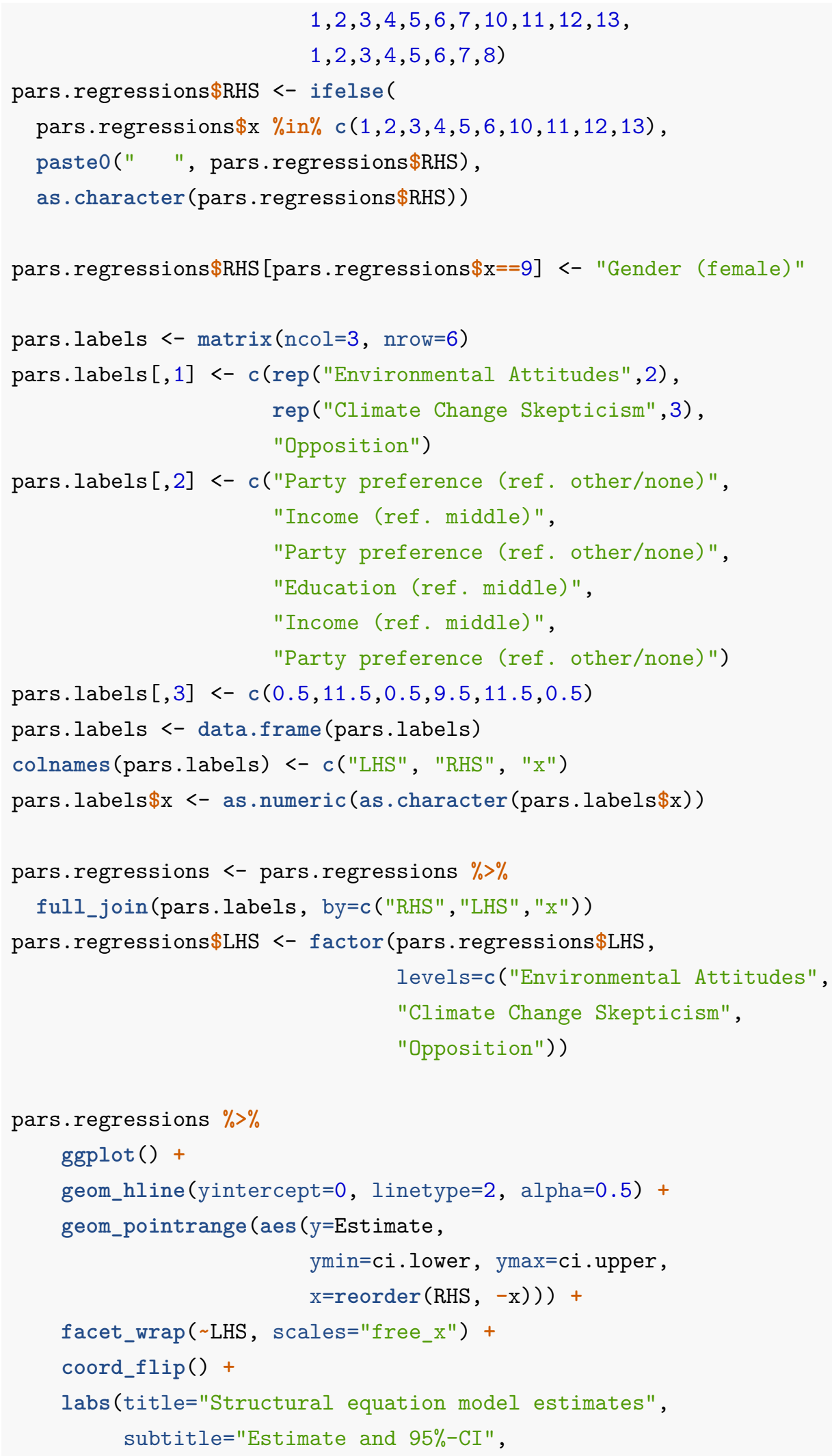


Structural equation model estimates

Estimate and $95 \%-\mathrm{Cl}$

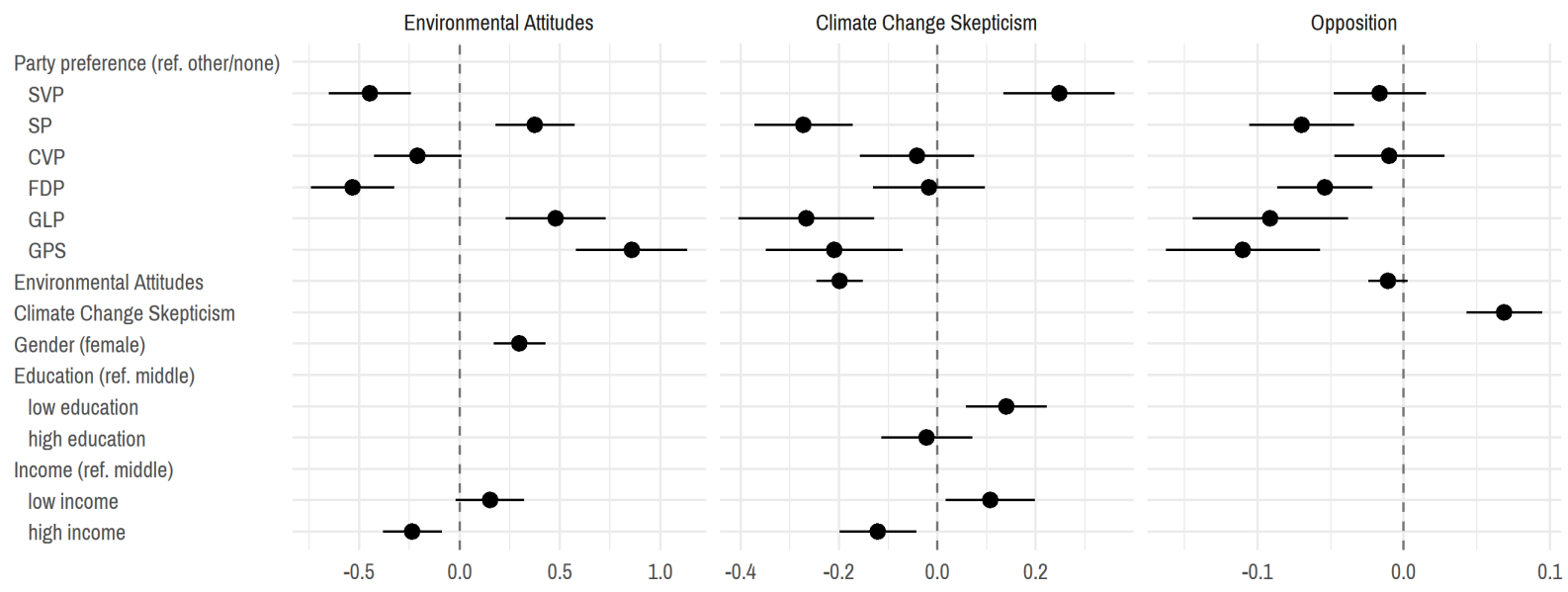

Figure 13: Structural equation model regression results.

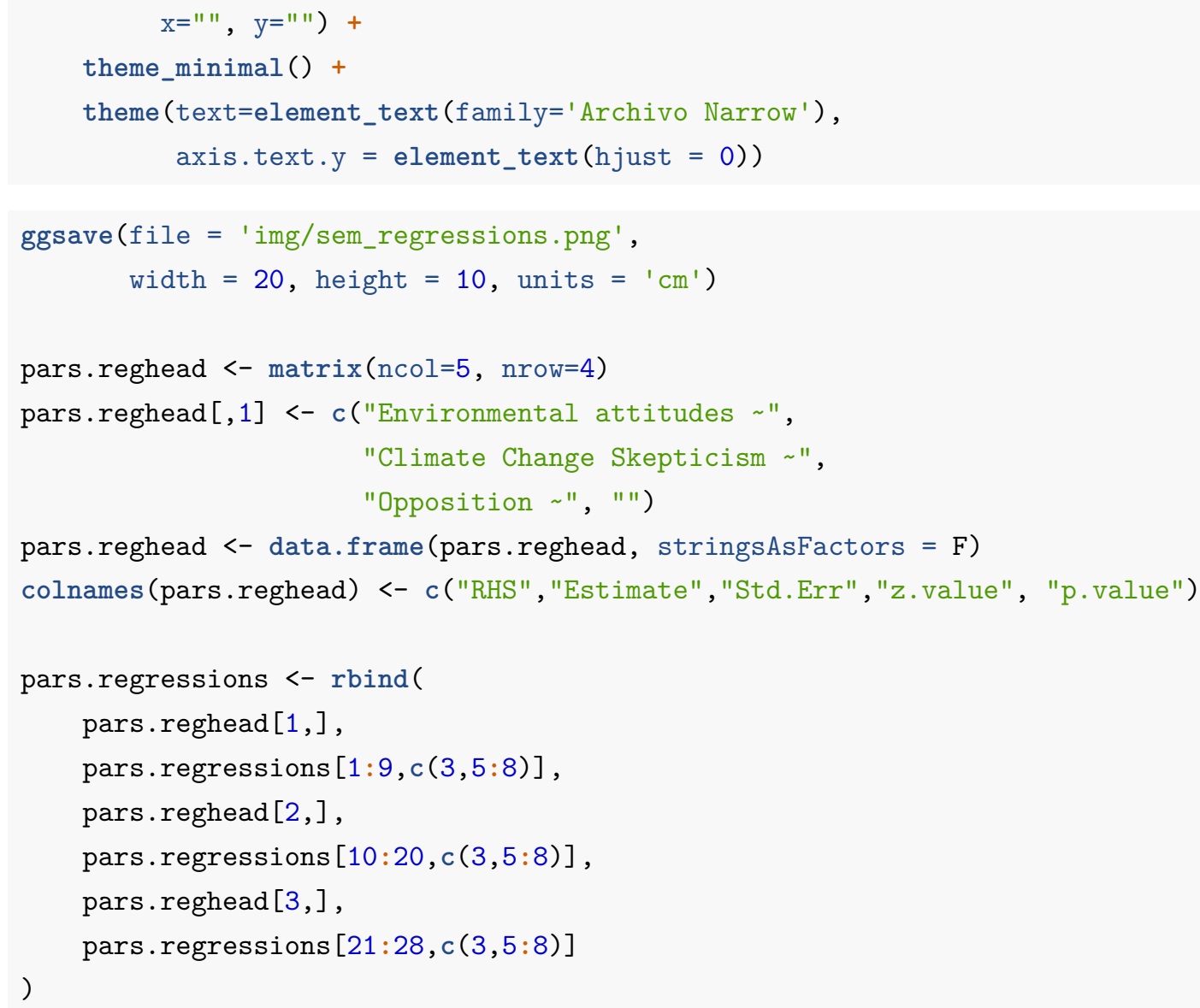




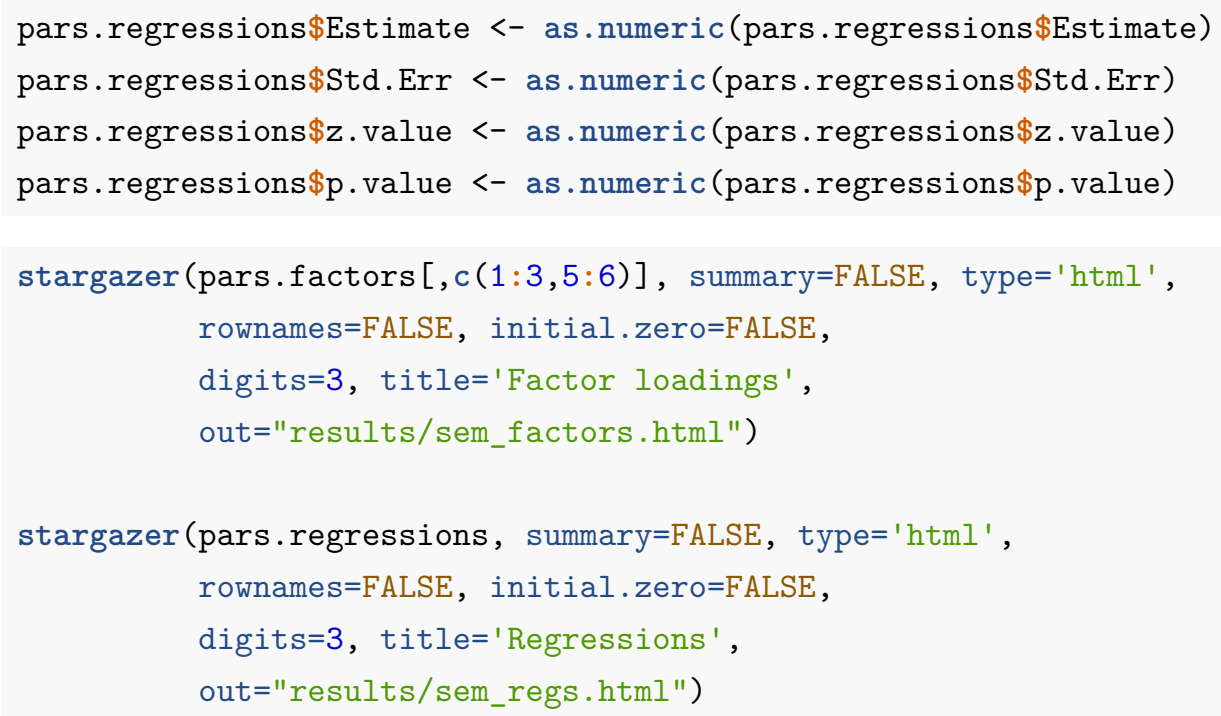

\subsection{A closer look at the latent variables}

The used R package lavaan allows to extract the predicted latent variables for opposition, climate change skepticism and environmental attitudes. A closer look at those latent variables by party preference allow for further insights how those concepts are influenced political preferences.

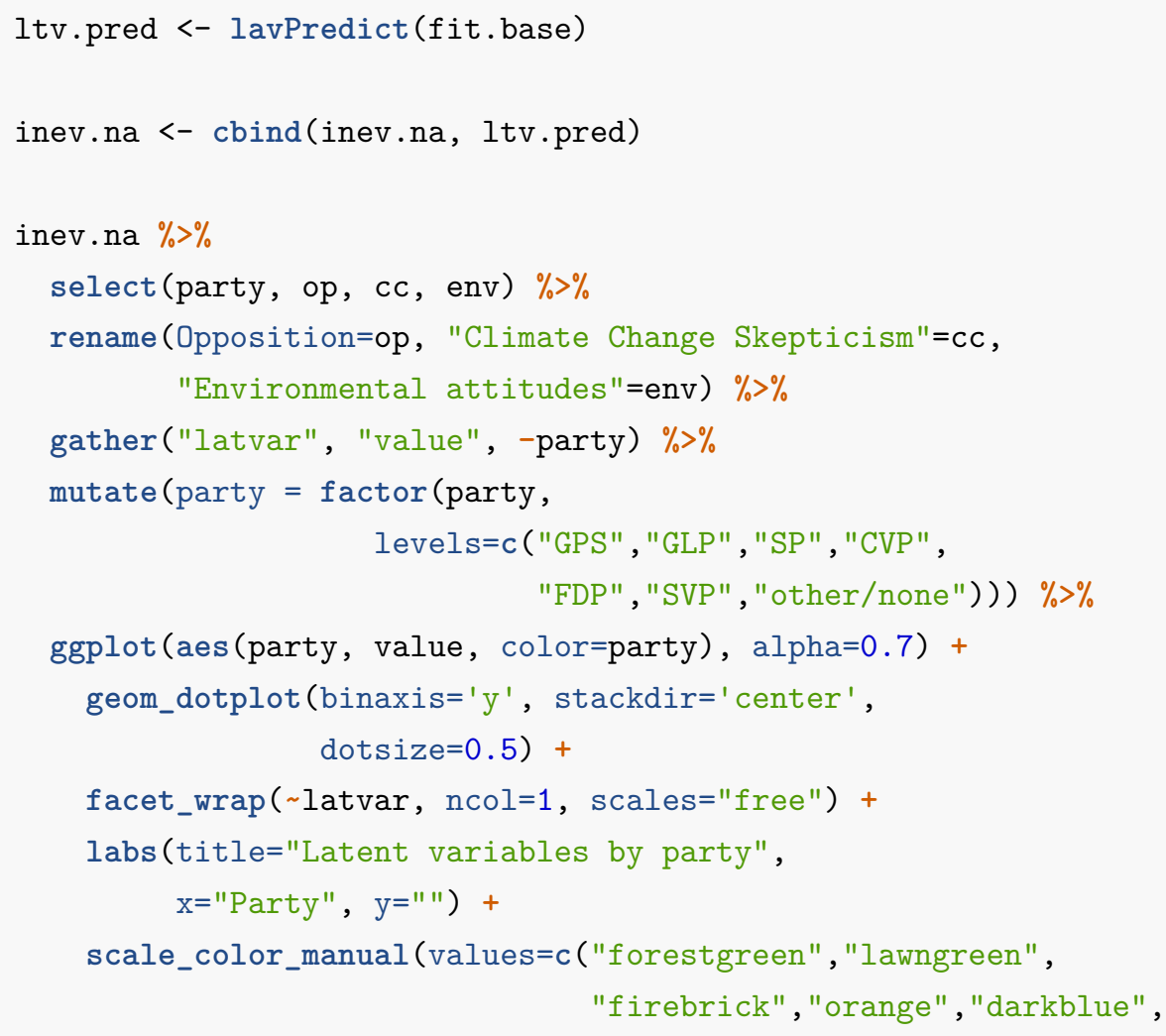




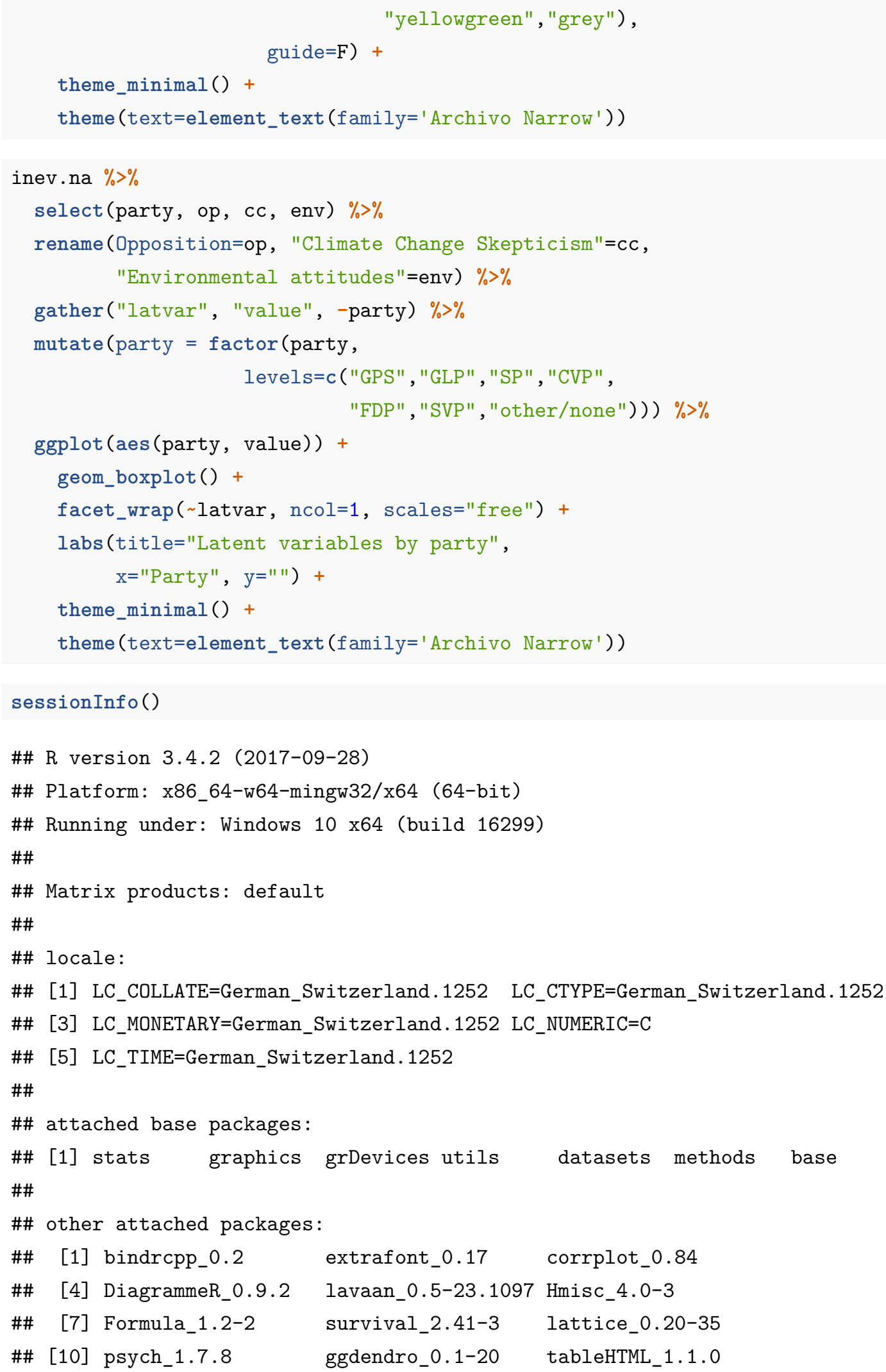




\section{Latent variables by party}
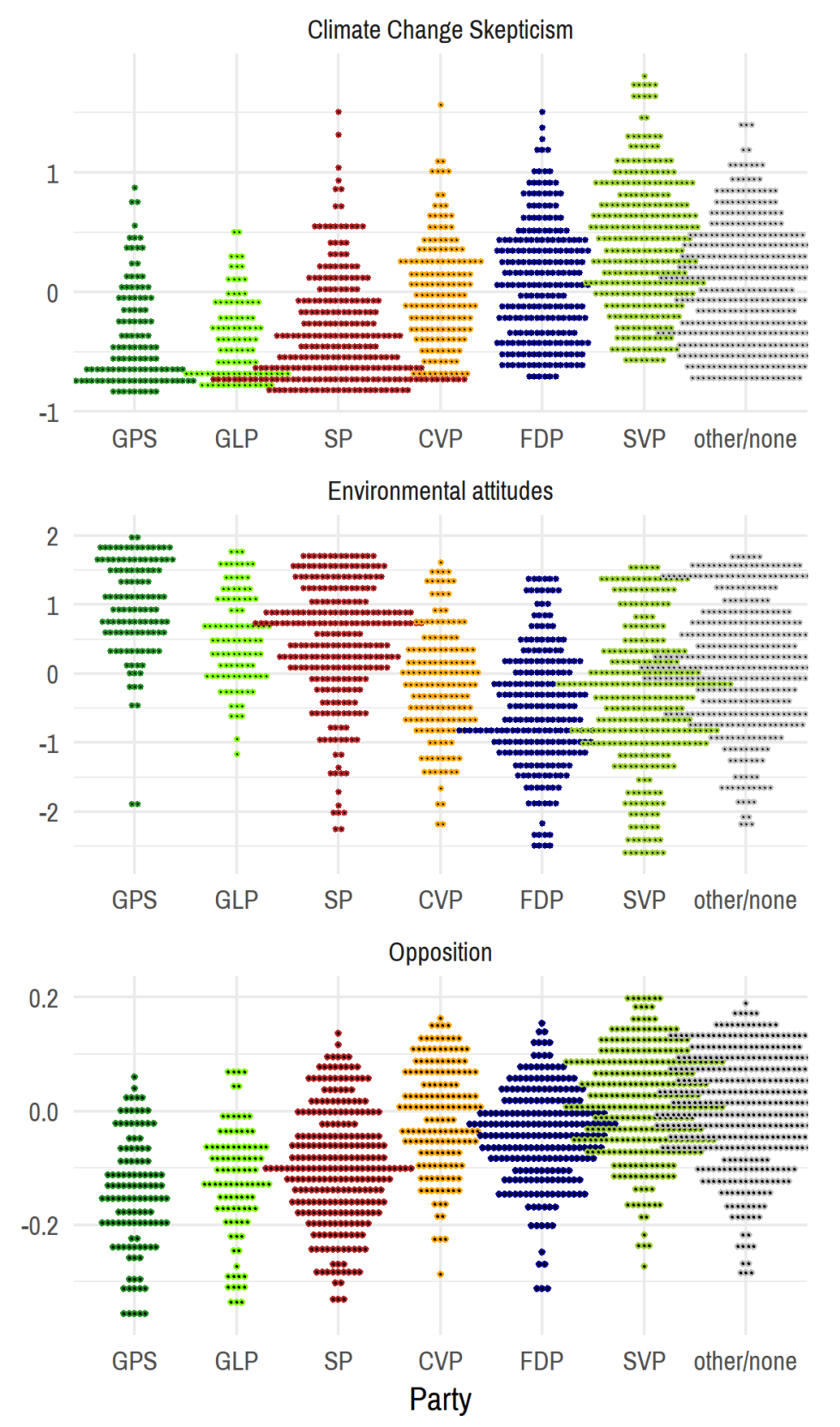

Figure 14: Latent variables by political ideology 


\section{Latent variables by party}
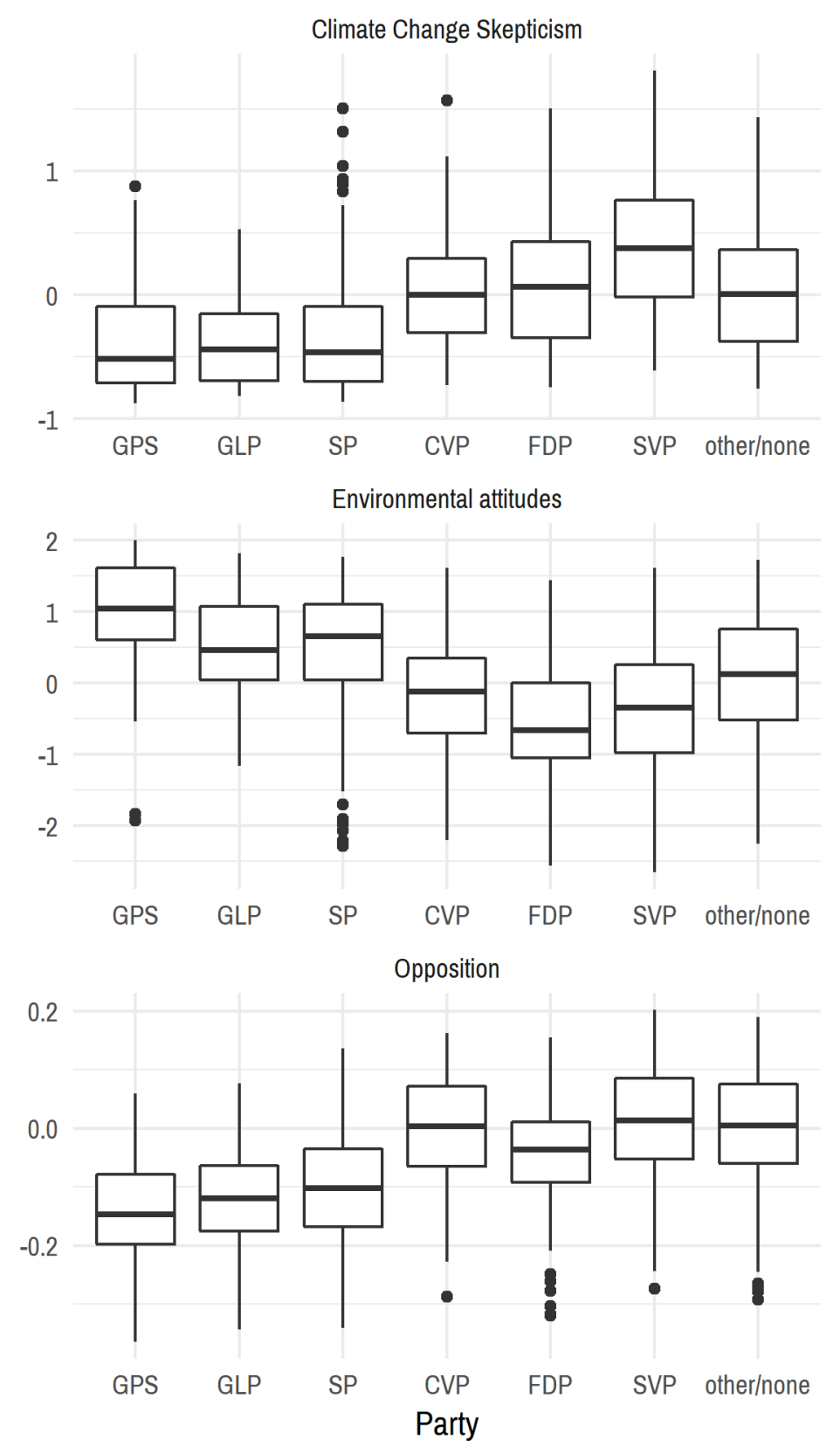

Figure 15: Latent variables by political ideology 


\begin{tabular}{|c|c|c|c|c|}
\hline \#\# & [13] & NbClust_3.0 & cluster_2.0.6 & pvclust_2.0-0 \\
\hline \#\# & {$[16]$} & factoextra_1.0.5 & dplyr_0.7.4 & purrr_0.2.4 \\
\hline \#\# & {$[19]$} & readr_1.1.1 & tidyr_0.7.2 & tibble_1.3.4 \\
\hline \#\# & [22] & ggplot2_2.2.1 & tidyverse_1.1.1 & pacman_0.4.6 \\
\hline \#\# & & & & \\
\hline \#\# & & d via a namespace & (and not attached): & \\
\hline \#\# & {$[1]$} & nlme_3.1-131 & lubridate_1.7.1 & RColorBrewer_1.1-2 \\
\hline \#\# & [4] & httr_1.3.1 & rprojroot_1.2 & tools_3.4.2 \\
\hline \#\# & {$[7]$} & backports_1.1.1 & R6_2.2.2 & rpart_4.1-11 \\
\hline \#\# & {$[10]$} & lazyeval_0.2.1 & colorspace_1.3-2 & nnet_7.3-12 \\
\hline \#\# & {$[13]$} & tidyselect_0.2.3 & gridExtra_2.3 & mnormt_1.5-5 \\
\hline \#\# & {$[16]$} & extrafontdb_1.0 & compiler_3.4.2 & rvest_0.3.2 \\
\hline \#\# & [19] & htmlTable_1.9 & $\mathrm{xml2} \_1.1 .1$ & influenceR_0.1.0 \\
\hline \#\# & {$[22]$} & labeling_0.3 & bookdown_0.5 & scales_0.5.0 \\
\hline \#\# & {$[25]$} & checkmate_1.8.5 & quadprog_1.5-5 & stringr_1.2.0 \\
\hline \#\# & {$[28]$} & digest_0.6.12 & pbivnorm_0.6.0 & foreign_0.8-69 \\
\hline \#\# & [31] & rmarkdown_1.6 & base64enc_0.1-3 & pkgconfig_2.0.1 \\
\hline \#\# & [34] & htmltools_0.3.6 & htmlwidgets_0.9 & rlang_0.1.4 \\
\hline \#\# & {$[37]$} & readxl_1.0.0 & rstudioapi_0.7 & bindr_0.1 \\
\hline \#\# & {$[40]$} & visNetwork_2.0.1 & jsonlite_1.5 & acepack_1.4.1 \\
\hline \#\# & {$[43]$} & rgexf_0.15.3 & magrittr_1.5 & Matrix_1.2-11 \\
\hline \#\# & [46] & Rcpp_0.12.13 & munsell_0.4.3 & viridis_0.4.0 \\
\hline \#\# & {$[49]$} & stringi_1.1.5 & yaml_2.1.14 & MASS_7.3-47 \\
\hline \#\# & [52] & plyr_1.8.4 & grid_3.4.2 & parallel_3.4.2 \\
\hline \#\# & {$[55]$} & ggrepel_0.7.0 & forcats_0.2.0 & haven_1.1.0 \\
\hline \#\# & {$[58]$} & splines_3.4.2 & hms_0.3 & knitr_1.17 \\
\hline \#\# & {$[61]$} & ggpubr_0.1.5 & igraph_1.1.2 & reshape2_1.4.2 \\
\hline \#\# & [64] & stats4_3.4.2 & XML_3.98-1.9 & glue_1.2.0 \\
\hline \#\# & [67] & evaluate_0.10.1 & downloader_0.4 & latticeExtra_0.6-28 \\
\hline \#\# & {$[70]$} & data.table_1.10.4-3 & 3 modelr_0.1.1 & Rttf2pt1_1.3.6 \\
\hline \#\# & [73] & cellranger_1.1.0 & gtable_0.2.0 & assertthat_0.2.0 \\
\hline \#\# & {$[76]$} & broom_0.4.2 & viridisLite_0.2.0 & Rook_1.1-1 \\
\hline \#\# & & brew_1.0-6 & & \\
\hline
\end{tabular}

